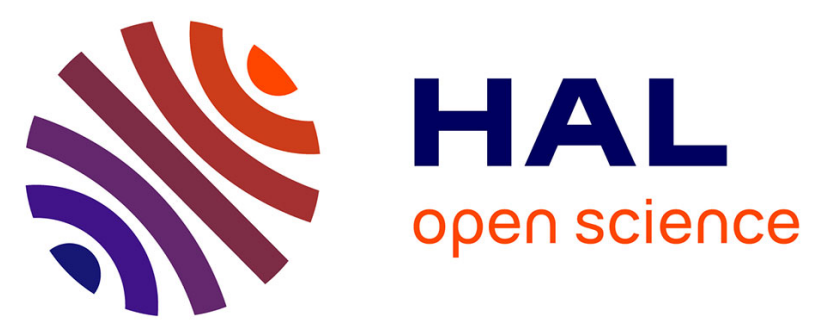

\title{
Cobalt-Mediated Radical Polymerization of Acrylonitrile: Kinetics Investigations and DFT Calculations
}

Antoine Debuigne, Catherine Michaux, Christine Jérôme, Robert Jérôme, Rinaldo Poli, Christophe Detrembleur

\section{To cite this version:}

Antoine Debuigne, Catherine Michaux, Christine Jérôme, Robert Jérôme, Rinaldo Poli, et al.. CobaltMediated Radical Polymerization of Acrylonitrile: Kinetics Investigations and DFT Calculations. Chemistry - A European Journal, 2008, 14 (25), pp.7623-7637. 10.1002/chem.200800371. hal03191507

\section{HAL Id: hal-03191507 https://hal.science/hal-03191507}

Submitted on 7 Apr 2021

HAL is a multi-disciplinary open access archive for the deposit and dissemination of scientific research documents, whether they are published or not. The documents may come from teaching and research institutions in France or abroad, or from public or private research centers.
L'archive ouverte pluridisciplinaire HAL, est destinée au dépôt et à la diffusion de documents scientifiques de niveau recherche, publiés ou non, émanant des établissements d'enseignement et de recherche français ou étrangers, des laboratoires publics ou privés. 


\title{
Cobalt-Mediated Radical Polymerization of Acrylonitrile: Kinetics Investigations and DFT Calculations
}

\author{
Antoine Debuigne, ${ }^{[\mathrm{a}]}$ Catherine Michaux, ${ }^{[\mathrm{b}]}$ Christine Jérôme, ${ }^{[\mathrm{a}]}$ Robert Jérôme, ${ }^{[\mathrm{a}]}$ Rinaldo Poli*[c] \\ Christophe Detrembleur*[a]
}

\begin{abstract}
The successful controlled homopolymerization of acrylonitrile (AN) by cobalt-mediated radical polymerization (CMRP) is reported for the first time. As a rule, initiation of the polymerization was carried out starting from a conventional azo-initiator (V70) in the presence of bis(acetylacetonato $)$ cobalt(II) $\quad\left(\mathrm{Co}(\mathrm{acac})_{2}\right)$ but also by using organocobalt(III) adducts. Molar concentration ratios of the reactants, temperature and the solvent were tuned and the effect of these
\end{abstract}

parameters on the course of the polymerization is discussed in details. The best level of control was observed when the AN polymerization was initiated by an organocobalt(III) adduct at $0^{\circ} \mathrm{C}$ in dimethylsulfoxide. Under these conditions, poly(acrylonitrile) with a predictable molar mass and molar mass distribution as low as 1.1 were prepared. A combination of kinetic data, X-Ray analyses and DFT calculations were used to rationalize the results and to draw conclusions on the key role played by the solvent molecules in the process. These important mechanistic insights also permit to explain the unexpected "solvent effect" allowing the preparation of well-defined poly(vinyl acetate)- $b$-poly(acrylonitrile) by CMRP.

Keywords: controlled radical
polymerization $\cdot$ cobalt mediated
radical polymerization $\cdot$
acrylonitrile $\cdot$ DFT calculations

\section{Introduction}

Since the discovery of the Controlled Radical Polymerization (CRP) concept ${ }^{[1]}$ a variety of techniques have emerged and pushed back the bounds of possibilities in terms of control of vinyl monomer polymerization. ${ }^{[2-5]}$ Thus, in the last decade, CRP established itself as one of the most powerful techniques for the synthesis of novel (co)polymers with complex but well-defined architectures.

Among these CRP techniques, Cobalt Mediated Radical Polymerization (CMRP) ${ }^{[6-9]}$ distinguished itself by its ability to

[a] Dr. A. Debuigne, Prof. C. Jérôme,, Prof. R. Jérôme,, Dr. C. Detrembleur, Center for Education and Research on Macromolecules

University of Liège

Sart-Tilman, B6a, B-4000 Liège (Belgium)

Fax: (+32) 4-366 3497

E-mail: christophe.detrembleur@ulg.ac.be

[b] Dr. C. Michaux

Chimie Biologique Structurale lab, CPTS group

Facultés Universitaires Notre-Dame de la Paix (FUNDP)

61 rue de Bruxelles, B-5000, Namur

[c] Prof. R. Poli

Laboratoire de Chimie de Coordination,

UPR CNRS 8241 liée par convention à l'Université Paul Sabatier et à

l'Institut National Polytechnique de Toulouse,

205 Route de Narbonne, 31077 Toulouse, France

Fax: $(+33) 561553003$

E-mail : poli@1cc-toulouse.fr (E-mail) mediate the polymerization of very reactive monomers, a typical example of which being vinyl acetate (VAc). ${ }^{[9-15]}$ This method involves the temporary deactivation of the growing poly(vinyl acetate) chains with a cobalt complex. Following this controlled radical pathway, PVAc with predictable molar masses and low polydispersities was prepared in bulk but also in aqueous media. Recently, mechanistic aspects of the CMRP of VAc were investigated in details using very low molecular weight cobalt(III) adducts as CMRP initiators. ${ }^{[16]}$ Depending on the polymerization conditions, both Degenerative chain Transfer (DT) and Reversible Termination (RT) mechanisms were highlighted. Indeed, the CMRP of VAc was mainly driven towards a DT mechanism when carried out in bulk whereas addition of molecules able to coordinate the cobalt, i.e. water and pyridine, switched the mechanism towards RT. $[12,16]$

The ability of the CMRP process to provide novel well-defined PVAc containing copolymers of interest was also demonstrated, together with the derivatized $\mathrm{PVOH}$ containing copolymers obtained under basic treatment. The key step of the strategy was the initiation of a comonomer using a PVAc-Co(acac)2 macroinitiator preformed by CMRP. Among the comonomers used are styrene, ${ }^{[17}$, ${ }^{18]}$ octene, ${ }^{[19]}$ ethylene, ${ }^{[19]} N$-vinyl pyrrolidone ${ }^{[20]}$ and more recently acrylonitrile. $^{[21]}$ In this last case, the controlled character of $\mathrm{AN}$ polymerization initiated at $0^{\circ} \mathrm{C}$ from the PVAc macroinitiator was clearly established provided that dimethylformamide (DMF) was used as the solvent. These PVAc- $b$-PAN block copolymers with narrow molecular weight distribution were then successfully derivatized into amphiphilic PVOH- $b$-PAN or hydrosoluble PVOH$b$-PAA under adequate hydrolysis treatment. These well-defined copolymers are interesting as carbon nanoobject precursors and 
biocompatible $\mathrm{pH}$ responsive materials, respectively.

The huge potential of well-defined PAN based materials justifies the efforts invested in the development and the understanding of the CRP of AN, a challenging monomer because of its high reactivity and the polymer low solubility. For nitroxide mediated radical polymerization (NMP), ${ }^{[22-24]}$ atom transfer radical polymerization (ATRP) ${ }^{[25-27]}$ and radical addition fragmentation chain transfer (RAFT), ${ }^{[28-32]}$ the in-depth study of the AN homopolymerization was crucial for the engineering of well-defined PAN based copolymers. As reported recently, it was possible to control the radical polymerization of AN by CMRP initiated from a preformed PVAc-Co(acac) 2 macroinitiator at $0^{\circ} \mathrm{C}$ in DMF, leading to well-defined PVAc- $b$-PAN copolymers. ${ }^{[21]}$ However, these optimized experimental conditions could not be extrapolated to the homopolymerization of AN. Furthermore, the mechanism, particularly the crucial role of the solvent, was not clear.

This paper aims at addressing both questions and reports an in depth study of the AN homopolymerization by CMRP starting from a conventional azo-initiator (V-70) and cobalt(II)acetylacetonate complex $\left(\mathrm{Co}(\mathrm{acac})_{2}\right)$. The previously encountered difficulties to control the AN polymerization were overcome by adjusting the polymerization conditions, particularly the temperature and the solvent. Combination of kinetic data and DFT calculations were used to rationalize the results and to draw conclusions on the exact role played by the solvent in the process. In this respect, the modification of the cobalt complex reactivity by solvent or monomer coordination was considered. The coordination mode of the bis(acetylaceto)cobalt complex by DMF and DMSO was investigated, leading to the crystallization and X-ray structural characterization of the previously unreported $\mathrm{Co}(\mathrm{acac})_{2}(\mathrm{DMF})_{2}$ and $\mathrm{Co}(\mathrm{acac})_{2}(\mathrm{DMSO})_{2}$ complexes. Important mechanistic and synthetic insights into the polymerization of $\mathrm{AN}$ by CMRP were also achieved by using the low molecular weight cobalt(III) adducts as CMRP initiators. ${ }^{[16]}$

\section{Results and Discussion}

It has recently been demonstrated that the acrylonitrile polymerization can be properly controlled when initiated from a PVAc- $[\mathrm{Co}]$ macroinitiator preformed by the CMRP of VAc. The choice of solvent and temperature for this process were crucial. Indeed, PVAc- $b$-PAN with polydispersities as low as $1.2-1.3$ were prepared at $0^{\circ} \mathrm{C}$ in dimethylformamide, whereas copolymers with much broader molar mass distributions were recovered when anisole was used as solvent. ${ }^{[21]}$ Decreasing the polymerization temperature to $0^{\circ} \mathrm{C}$ allowed the polydispersity of the copolymer to be lowered to 1.1-1.2.

In light of these results, the AN polymerization was initiated at $30^{\circ} \mathrm{C}$ by V-70 in the presence of $\mathrm{Co}(\mathrm{acac}) 2$. Due to the DMF ligand power, it is likely that a DMF molecule coordinates to the free sites of the cobalt complexes, as was demonstrated for pyridine and water. ${ }^{[12,16]}$ Consequently, the CMRP process should be governed only by Reversible Termination of the propagating chains, as represented in Scheme 1. Under these experimental conditions, the polymerization medium became inhomogeneous and a grey suspension appeared after a few hours. The molar mass and the monomer conversion were monitored all along the polymerization. The data are reported in Table 1. Because of the inhomogeneity of the polymerization medium, each sample was obtained from a separate experiment stopped at a different time.

Table 1. CMRP of acrylonitrile (AN) initiated by $\mathrm{V}-70$ at $30^{\circ} \mathrm{C}$ in dimethylformamide (DMF). ${ }^{[\mathrm{a}]}$

\begin{tabular}{cccccc}
\hline Entry & $\begin{array}{c}\mathrm{t} \\
{[\mathrm{h}]}\end{array}$ & $\begin{array}{c}\mathrm{Conv}^{[\mathrm{b}]} \\
{[\%]}\end{array}$ & $\begin{array}{c}\mathrm{M}_{\mathrm{n} \mathrm{SEC}}{ }^{[\mathrm{cc}]} \\
{\left[\mathrm{g} \mathrm{mol}^{-1}\right]}\end{array}$ & $\begin{array}{c}\mathrm{M}_{\mathrm{nth}}{ }^{[\mathrm{d}]} \\
{\left[\mathrm{g} \mathrm{mol}^{-1}\right]}\end{array}$ & $\begin{array}{c}\mathrm{M}_{\mathrm{w}} / \\
\mathrm{M}_{\mathrm{n}}{ }^{\text {[e] }}\end{array}$ \\
\hline 1 & 2 & 2 & 2960 & 200 & 1.20 \\
2 & 4 & 11 & 4020 & 1100 & 1.64 \\
3 & 7 & 35 & 7200 & 3500 & 1.72 \\
4 & 17 & 64 & 9800 & 6500 & 1.80 \\
5 & 22 & 87 & 10100 & 8800 & 1.89 \\
\hline
\end{tabular}

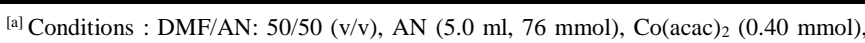
V-70 $(0.40 \mathrm{mmol}), 30^{\circ} \mathrm{C} .{ }^{[b]}$ Monomer conversion determined by gravimetry. ${ }^{[c]}$ The number-average molar mass determined by size exclusion chromatography $\left(\mathrm{M}_{\mathrm{n}} \mathrm{SEC}\right)$ in DMF with a poly(methyl methacrylate) calibration corrected by the Mark-Houwink equation (cfr experimental section). ${ }^{[d]}$ Theoretical molar mass calculated based on the $[\mathrm{AN}] /[\mathrm{Co}]$ ratio and conversion. ${ }^{[\mathrm{e}]} \mathrm{M}_{\mathrm{w}}$ : weight-average molecular weight.

Despite the appearance of a precipitate, the molar mass of the PAN increases with time and monomer conversion. However, the Mn were greater than the theoretical values determined by the [monomer]/[Co] molar ratio, especially at the beginning of the polymerization. This observation suggests that only a fraction of the cobalt complex exerts its controlling action in the early stage of the polymerization. Moreover, the molar mass distribution tends to broaden all along the polymerization (Mw-Mn 1.6-1.9). Therefore, under these conditions, only a poor control of the AN polymerization was achieved. This is not surprising considering the unexpected lack of solubility of PAN in DMF at $30^{\circ} \mathrm{C}$.

The possibility of a control of tacticity was considered, because isotactic PAN is less soluble than the atactic one in DMF. ${ }^{[33]}$ However, the ${ }^{13} \mathrm{C}$ spectrum of the PAN prepared by CMRP was typical of atactic PAN prepared by conventional radical polymerization (the ${ }^{13} \mathrm{C}$ NMR spectrum of the PAN sample presented in Table 1 entry 4 is provided as supporting information). In order to check whether $\mathrm{Co}(\mathrm{acac})_{2}$ may be responsible for this precipitation phenomenon, the free radical polymerization of $\mathrm{AN}$ was initiated at $30^{\circ} \mathrm{C}$ by V-70 in DMF. This experiment also led to precipitation.

In order to improve the PAN solubility in DMF during the

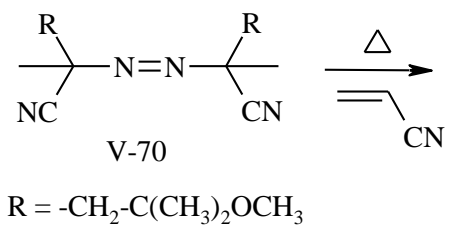

$\overbrace{\mathrm{NC}}^{+\mathrm{AN}}$

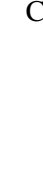

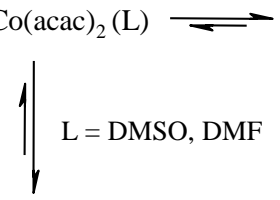<smiles>[R]C(C)(C)CC(C#N)CC(C#N)C(=O)OCc1ccccc1</smiles>

$\mathrm{Co}(\mathrm{acac})_{2}(\mathrm{~L})_{2}$ 
CMRP process, the temperature might be increased but this would be to the detriment of the control of the polymerization governed by the thermal cleavage of the $\mathrm{Co}-\mathrm{C}$ bond. In order to avoid these insolubility problems, the homopolymerization of AN was thus initiated by $\mathrm{V} 70$ in the presence of $\mathrm{Co}(\mathrm{acac})_{2}$ in a better solvent for PAN at $30^{\circ} \mathrm{C}$, i.e. DMSO (Scheme 1). As expected, the appearance of a precipitate was not observed in this case, the reaction medium remaining perfectly homogeneous all along the polymerization.

In order to properly evaluate the ability of $\mathrm{Co}(\mathrm{acac})_{2}$ to control the AN polymerization in DMSO at $30^{\circ} \mathrm{C}$, three experiments were conducted using equimolar amounts of $\mathrm{Co}(\mathrm{acac})_{2}$ and V-70 but changing the $[\mathrm{AN}] /[\mathrm{Co}]$ molar ratio. Kinetics data and the molecular parameters $\left(\mathrm{M}_{\mathrm{n}}, \mathrm{M}_{\mathrm{w}} / \mathrm{M}_{\mathrm{n}}\right)$ dependence on the monomer conversion are plotted in Figure 1. From the kinetic point of view, the three experiments present the same behavior. (Figure 1a) All of them showed only a very short induction period and the time dependence

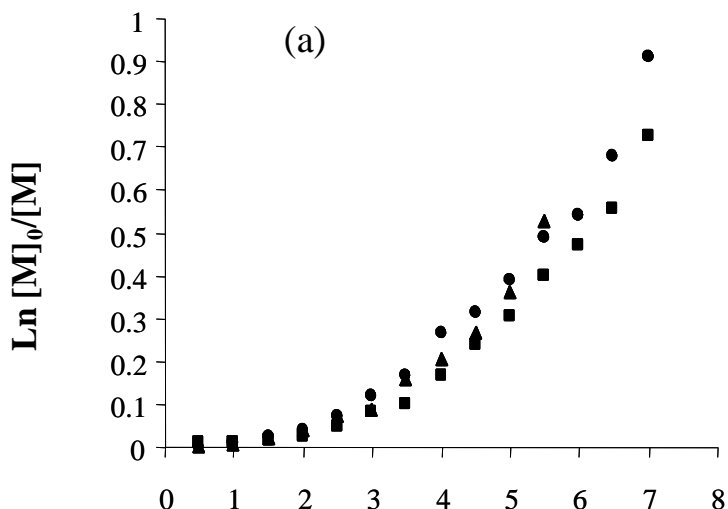

Time (h)

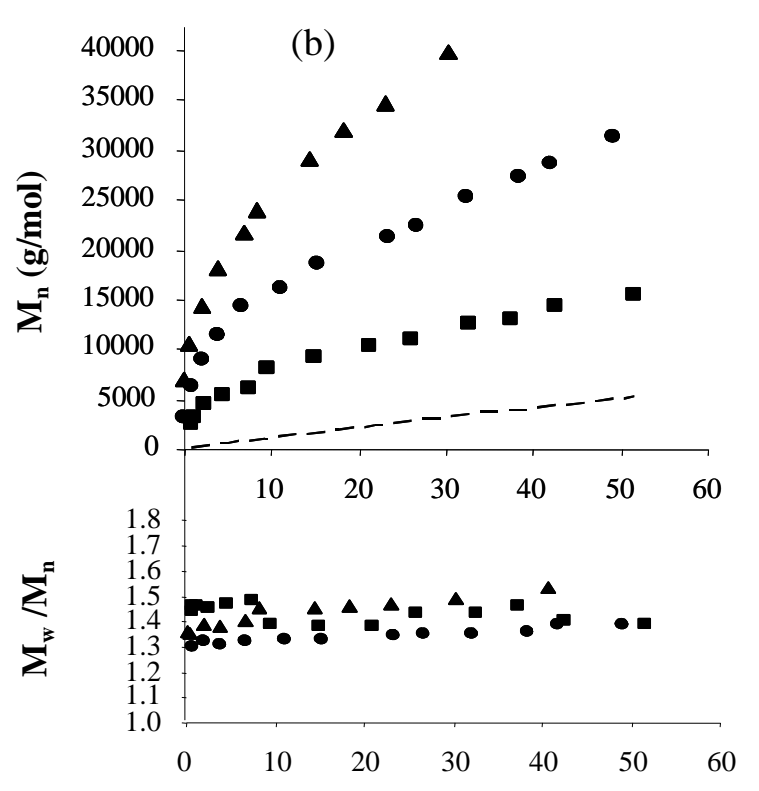

Conv. (\%)

Figure 1. (a) Time dependence of $\ln [\mathrm{M}]_{0} /[\mathrm{M}]$ (M: monomer); (b) dependence of the poly(acrylonitrile) molar mass $\left(\mathrm{M}_{\mathrm{n}}\right)$ and molar mass distribution $\left(\mathrm{M}_{\mathrm{w}} / \mathrm{M}_{\mathrm{n}}\right)$ on the monomer conversion for the acrylonitrile (AN) polymerization initiated by $\mathrm{V}-70$ in dimethylsulfoxide (DMSO) at $30^{\circ} \mathrm{C}$ using different $[\mathrm{AN}] /\left[\mathrm{Co}(\mathrm{acac})_{2}\right]$ ratios. (a) $[\mathrm{AN}] /\left[\mathrm{Co}(\mathrm{acac})_{2}\right]=188\left(\mathrm{M}_{\mathrm{n} \text { th. } 100 \%}=10000 \mathrm{~g} / \mathrm{mol}\right),(\bullet)[\mathrm{AN}] /\left[\mathrm{Co}(\mathrm{acac})_{2}\right]=376\left(\mathrm{M}_{\mathrm{n}}\right.$ th, $100 \%=20000 \mathrm{~g} / \mathrm{mol}),(\boldsymbol{\Delta})[\mathrm{AN}] /\left[\mathrm{Co}(\mathrm{acac})_{2}\right]=752\left(\mathrm{M}_{\mathrm{n}}\right.$ th, $\left.100 \%=40000 \mathrm{~g} / \mathrm{mol}\right)$. For all experiments, $[\mathrm{V}-70] /\left[\mathrm{Co}(\mathrm{acac})_{2}\right]=1$ and DMSO/AN: $50 / 50(\mathrm{v} / \mathrm{v})$. The dotted line represents the theoretical dependence of the molar mass with the monomer conversion when $[\mathrm{AN}] /\left[\mathrm{Co}(\mathrm{acac})_{2}\right]=188$. of the $\ln [\mathrm{M}]_{0} /[\mathrm{M}]$ function is not linear at higher values. In order to explain this profile it is interesting to compare these results with those of the VAc polymerization. The CMRP of VAc conducted in bulk in the absence of any coordinating ligands showed a much longer induction time, because radical trapping by the Co complex is irreversible and the polymerization was inhibited until most of the $\mathrm{Co}(\mathrm{acac})_{2}$ available in the medium was converted into the alkyl cobalt(III) dormant species. Then, further generation of radicals allowed the polymerization to proceed by degenerative chain transfer (DT). However, no induction period was observed in the presence of pyridine, because coordination of this compound at the same time stabilizes the cobalt(II) radical trap by formation of $\mathrm{Co}(\mathrm{acac})_{2}(\mathrm{py})_{2}$, rendering a reversible termination mechanism possible since the early stages of the polymerization, and blocks the open coordination site on the cobalt(III) dormant species, rendering the alternative degenerate transfer mechanism impossible. ${ }^{[12]}$ In the case of the AN homopolymerization carried out in DMF or DMSO, it is reasonable to assume that the solvent molecules are able to function as ligands toward the cobalt(II) and cobalt(III) species (cf. Scheme 1), largely removing the long induction period featured by the bulk polymerization system. The initial curvature of the first order kinetics plot may result from the slow decomposition of the azo-initiator, producing a growing concentration of chaincontrolling species with the reaction time.

Concerning the molecular parameters (Figure 1b), it clearly appears that the PAN molar masses increase with the monomer conversion. As expected for a controlled process, the PAN molar mass strongly depends on the $[\mathrm{AN}] /[\mathrm{Co}]$ molar ratio for a given monomer conversion. Higher PAN molar masses were obtained when high $[\mathrm{AN}] /[\mathrm{Co}]$ ratio was used. However, in all cases, the experimental molar masses were higher than the theoretical values calculated on the basis of the [monomer]/[Co] ratio. This fact is illustrated in Figure $1 \mathrm{~b}$ showing the discrepancy between the theoretical dotted curve and the corresponding full lines. This observation also confirmed that all the cobalt is not active as a controlling agent. Moreover, the evolution of $\mathrm{Mn}$ with the conversion did not follow an ideal linear behavior, especially at low monomer conversion. This deviation can also be explained by the slow initiation and consequently, the initial slow increase of the number of growing chains. Indeed, the efficiency factor ( $\mathrm{f}=\mathrm{M}_{\mathrm{n}}$, th / $\mathrm{M}_{\mathrm{n}, \exp }$ ) increased along the polymerization (f was equal to 0.05 and 0.30 at $3 \%$ and $40 \%$ monomer conversion, respectively). Finally, the polydispersity was in the range 1.3-1.5 which is better than the same experiment carried out in DMF (Mw/Mn 1.6-1.9). In summary, although not perfect, the CMRP process can impart control to the AN homopolymerization carried out in DMSO at $30^{\circ} \mathrm{C}$, as illustrated by the clear shift of the SEC chromatograms with the time towards higher molecular weight (Figure 2).

As the amount of cobalt involved in the equilibrium at the beginning of the reaction is quite low, we decreased the [V$70]_{0} /\left[\mathrm{Co}(\mathrm{acac})_{2}\right]_{0}$ ratio from 1 to 0.25 while maintaining a constant $[\mathrm{AN}] /[\mathrm{Co}]$ ratio. The results of these experiments are reported in Figure 3. For the reasons exposed above, the induction period was short and the time dependence of the $\ln [\mathrm{M}]_{0} /[\mathrm{M}]$ function was not linear, independent of the $[\mathrm{V}-70] /[\mathrm{Co}]$ ratio. (Figure 3a) However, the polymerization rate was lower for lower azo-initiator amounts. Importantly, the possibility to promote the polymerization of AN in the presence of a large excess of Co $([\mathrm{V}-70] /[\mathrm{Co}]=0.25)$ is additional proof that most of the metal is not involved in the equilibrium that regulates the AN polymerization control. 
From the molecular parameters point of view, the same molar masses might be expected in all the experiments because the same $[\mathrm{AN}] /[\mathrm{Co}]$ ratio was used. However, at any given conversion, higher molar masses were observed for lower [V-70]/[Co] ratios (Figure $3 b)$. This observation may again be explained on the basis of the slow increase of the number of active chains, as follows. For lower [V-70] concentrations, the radical generation and the consequent increase of the number of PAN chains is slower. Based on the V-70 half-life at $30^{\circ} \mathrm{C}\left(\mathrm{t}^{1 / 2}=600 \mathrm{~min}\right)$, it is possible to calculate the amount of decomposed V-70 in each experiment as shown in equation 1 .

$$
[\mathrm{V}-70]_{\mathrm{t}} /[\mathrm{V}-70]_{0}=\exp ^{-\mathrm{kt}} \quad\left(\text { where } \mathrm{k}=(\ln 2) / \mathrm{t}^{1 / 2}\right)
$$

Table 2. Comparison of the amount of azo-initiator (V-70) decomposed at $26 \%$ conversion for the CMRP of acrylonitrile (AN) in dimethylsulfoxide (DMSO). ${ }^{[a]}$

\begin{tabular}{|c|c|c|c|c|c|c|}
\hline Entry & $\begin{array}{c}{[\mathrm{V}-70]} \\
/[\mathrm{Co}]\end{array}$ & $\begin{array}{l}\mathrm{n} \mathrm{v}{ }^{[\mathrm{b}}{ }^{[\mathrm{b}]} \\
{[\mathrm{mmol}]}\end{array}$ & $\begin{array}{c}\mathrm{t} \\
{[\mathrm{min}]}\end{array}$ & $\begin{array}{c}\text { nv-70 decomp. }{ }^{\text {[c] }} \\
{[\mathrm{mmol}]}\end{array}$ & $\begin{array}{l}{[\mathrm{AN}]_{\text {conv. }} /} \\
{[\mathrm{V}-70]_{\text {decomp. }}}\end{array}$ & $\begin{array}{l}\mathrm{M}_{\mathrm{nSEC}}{ }^{[\mathrm{d}]} \\
{\left[\mathrm{g} / \mathrm{mol}^{-1}\right]}\end{array}$ \\
\hline 1 & $1(\mathbf{m})^{[\mathrm{e}]}$ & 0.40 & 300 & 0.116 & 170 & 10900 \\
\hline 2 & $0.5(\bullet)^{[\mathrm{e}]}$ & 0.20 & 390 & 0.072 & 285 & 17800 \\
\hline 3 & $0.25(\boldsymbol{\Delta})^{[\mathrm{e}]}$ & 0.10 & 780 & 0.059 & 335 & 20800 \\
\hline
\end{tabular}

[a] Conditions: $30^{\circ} \mathrm{C}$, DMSO/AN: 50/50 (v/v), Co(acac) $2(0.40 \mathrm{mmol})$, AN $(76 \mathrm{mmol})$ ${ }^{[b]}$ Initial amount of V-70. ${ }^{[c]}$ Amount of decomposed V-70 after $t$ min. ${ }^{[d]}$ The numberaverage molar mass determined by size exclusion chromatography $\left(M_{n} \operatorname{SEC}\right)$ in dimethylformamide with a poly(methyl methacrylate) calibration corrected by the Mark-Houwink equation (cfr experimental section). ${ }^{[\mathrm{e}]} c f$. symbols in figure $3 \mathrm{~b}$.

For the different experiments, these values can be calculated and compared for time values corresponding to the same conversion. For instance, the amounts of V-70 that has decomposed at a $26 \%$ monomer conversion for the CMRP of AN in DMSO carried out at $30^{\circ} \mathrm{C}$ using different $[\mathrm{V}-70] /[\mathrm{Co}]$ ratios are presented in Table 2. The amount of radicals generated by decomposition of V-70 is clearly lower for lower initial amount of V-70 (entry 3, Table 2), in spite of the longer reaction time. Moreover, it is interesting to note that the PAN molar mass doubled when the [converted $\mathrm{AN}] /[$ decomposed V-70] ratio doubled. (Compare Table 2 entries 1 and 3).

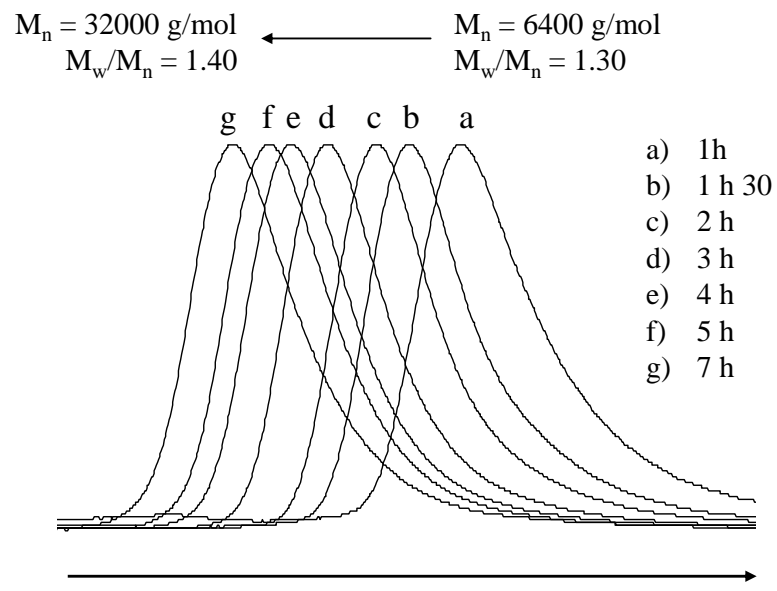

Elution time

Figure 2. Time evolution of the size exclusion chromatograms for the acrylonitrile (AN) polymerization initiated at $30^{\circ} \mathrm{C}$ in dimethylsulfoxide by $\mathrm{V}-70$ in the presence of $\mathrm{Co}(\mathrm{acac})_{2} .[\mathrm{AN}] /\left[\mathrm{Co}(\mathrm{acac})_{2}\right] /[\mathrm{V}-70]=376 / 1 / 1 . \quad \mathrm{M}_{\mathrm{n}}$ and $\mathrm{M}_{\mathrm{w}}$ are number-average and weight-average molecular weight, respectively.
Thus, both the lack of linearity in the kinetics and the dependence of the molar mass with the monomer conversion may be explained by the change in the number of growing chains along the polymerization. In order to provide additional supporting evidence, the AN polymerization was initiated from a low molecular weight cobalt(III) adduct which mimics the dormant species (Scheme 2), namely the Co-capped short PVAc oligomer recently reported by us. ${ }^{[16]}$ This consists of a cobalt adduct having less than 4 vinyl acetate units on average end-capped by $\mathrm{Co}(\mathrm{acac})_{2}\left(\mathrm{R}_{0}-\left(\mathrm{CH}_{2}-\right.\right.$ $\mathrm{CHOAc})_{n}-\mathrm{Co}(\mathrm{acac})_{2}$ with $n<4 ; \mathrm{R}_{0}=$ primary radical from the $\mathrm{V}-70$ decomposition). Indeed, using such a CMRP initiator in the absence of $\mathrm{V}-70$, the number of chains should be constant and provide linear $\ln [\mathrm{M}]_{0} /[\mathrm{M}]$ vs time and Mn vs monomer conversion plots as long as initiation is fast compared to propagation. An AN homopolymerization experiment using this initiator was carried out in DMSO at $30^{\circ} \mathrm{C}$ and $0^{\circ} \mathrm{C}$ and the results are shown in Figure 4.
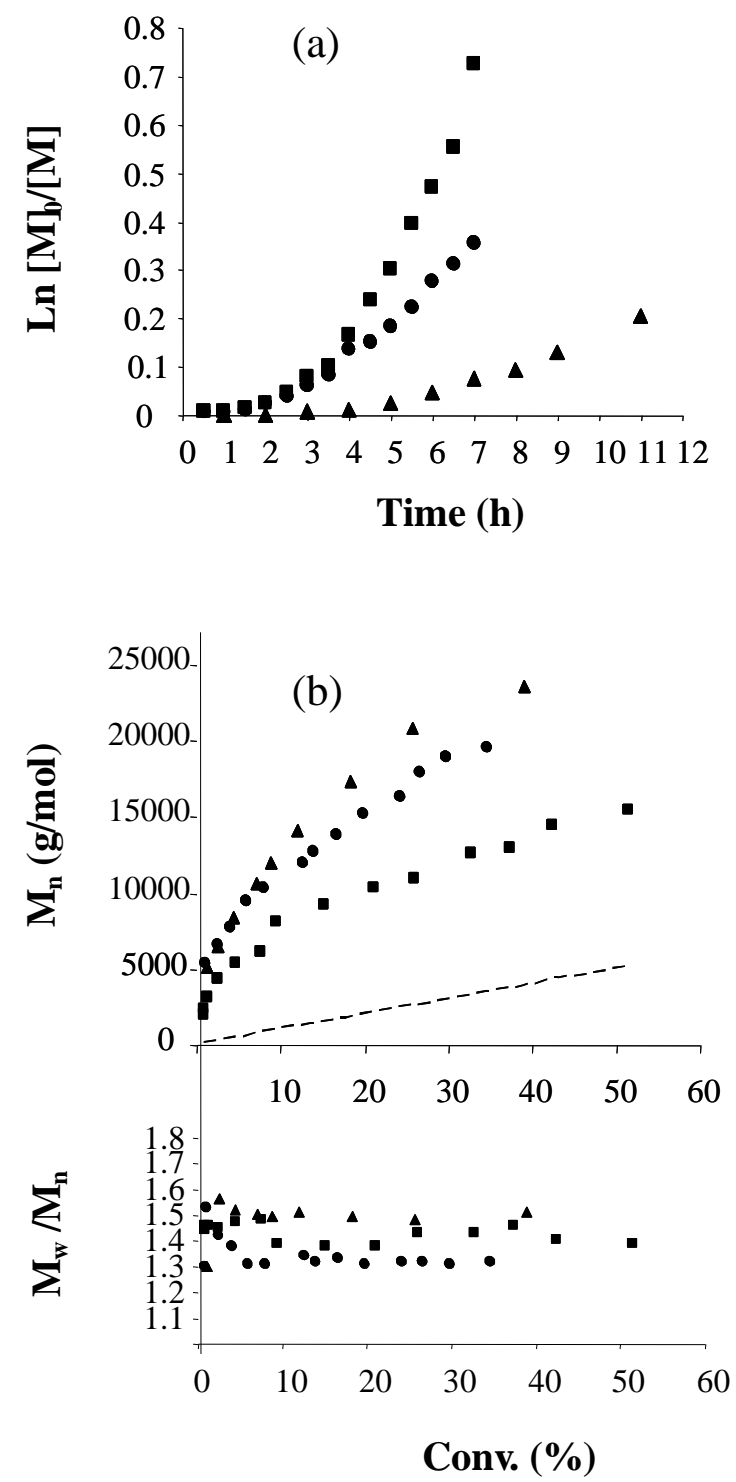

Figure 3. (a) Time dependence of $\ln [\mathrm{M}]_{0} /[\mathrm{M}]$ (M: monomer); (b) dependence of the poly(acrylonitrile) molar mass $\left(\mathrm{M}_{\mathrm{n}}\right)$ and molar mass distribution $\left(\mathrm{M}_{\mathrm{w}} / \mathrm{M}_{\mathrm{n}}\right)$ on the monomer conversion for the acrylonitrile (AN) polymerization initiated by the V-70 in dimethylsulfoxide (DMSO) at $30^{\circ} \mathrm{C}$ using different $\left[\mathrm{Co}(\mathrm{acac})_{2}\right] /[\mathrm{V}$ $70]$ ratios. $(\bullet)\left[\mathrm{Co}(\mathrm{acac})_{2}\right] /[\mathrm{V}-70]=1.0,(\bullet)\left[\mathrm{Co}(\mathrm{acac})_{2}\right] /[\mathrm{V}-70]$ ratios $=0.5,(\boldsymbol{\Delta})$ $\left[\mathrm{Co}(\text { acac })_{2}\right] /[\mathrm{V}-70]=0.25$. For all experiments, $[\mathrm{AN}] /\left[\mathrm{Co}(\mathrm{acac})_{2}\right]=188$ and DMSO/AN: $50 / 50(\mathrm{v} / \mathrm{v})$. The dotted line represents the theoretical dependence of the molar mass with the monomer conversion. 


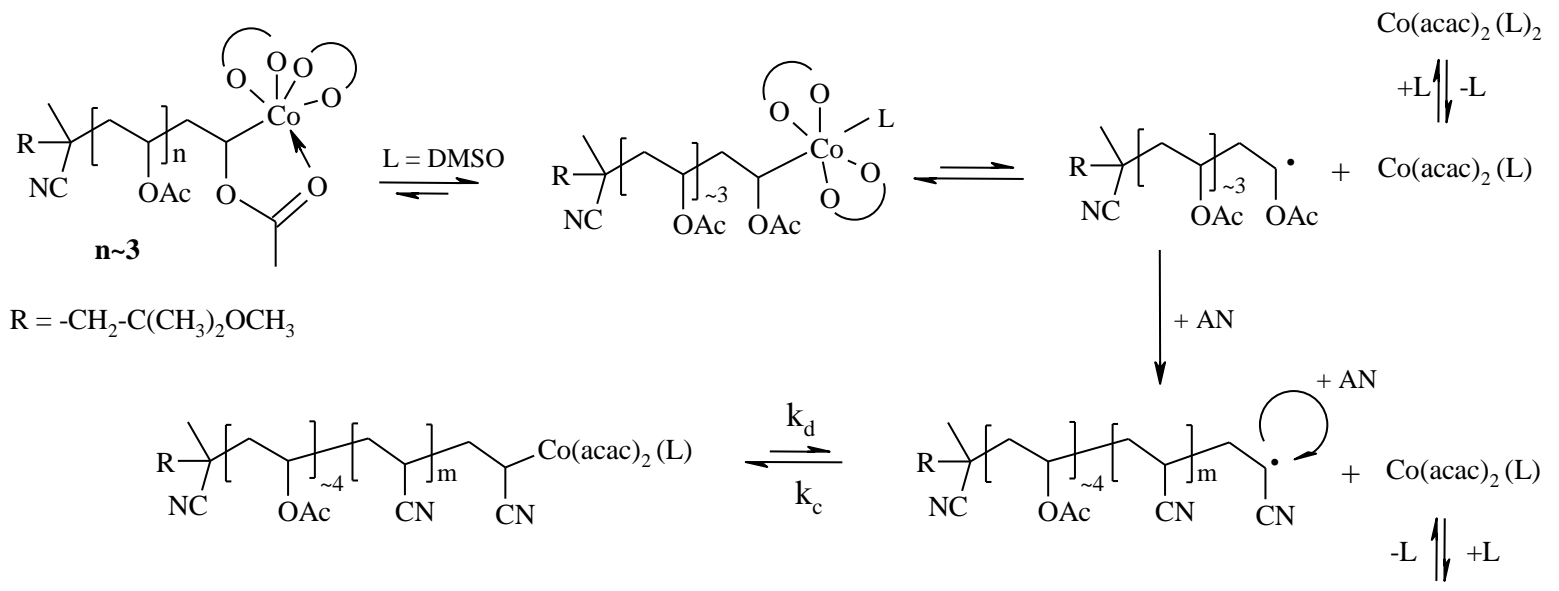

$\mathrm{Co}(\mathrm{acac})_{2}(\mathrm{~L})_{2}$

Scheme 2. Homopolymerization of acrylonitrile (AN) initiated by a low molecular cobalt(III) adduct in dimethylsulfoxide (DMSO)
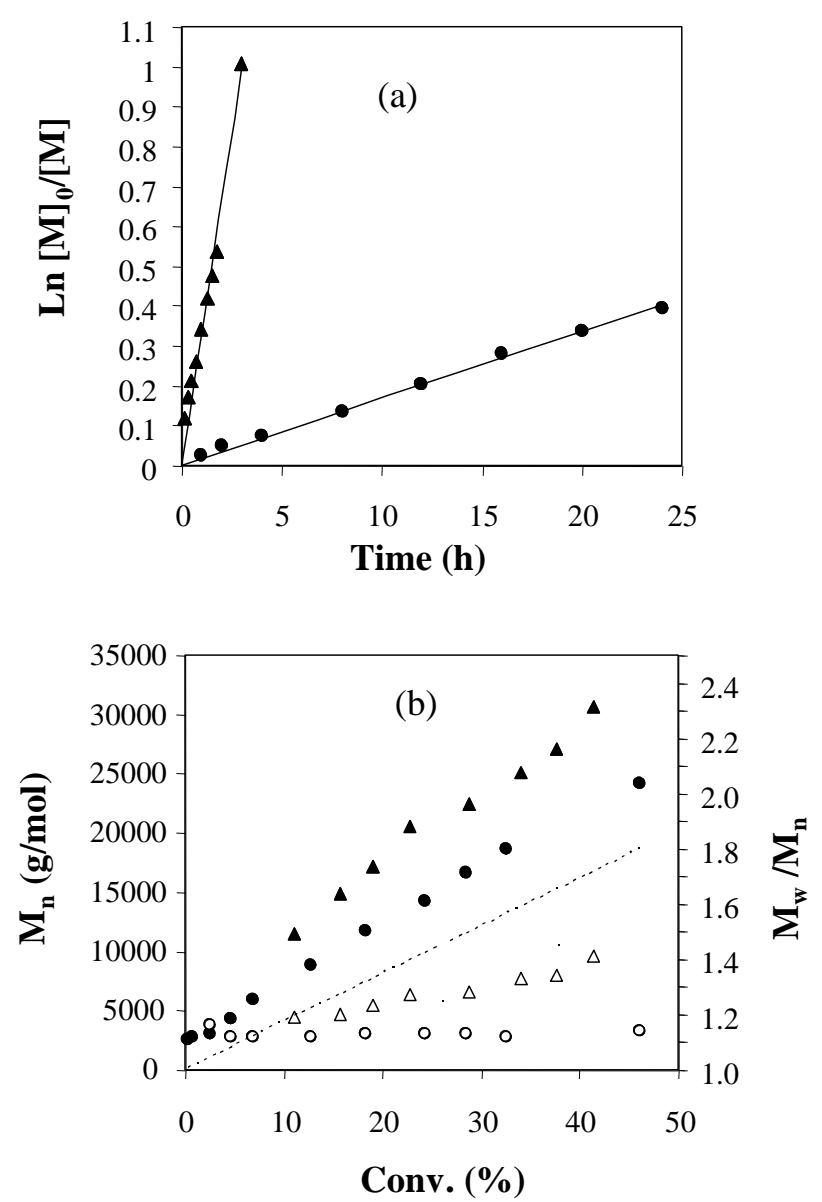

Figure 4. (a) Time dependence of $\ln [\mathrm{M}]_{0} /[\mathrm{M}]$ (M: monomer); (b) dependence of the molar mass $\left(\mathrm{M}_{\mathrm{n}}\right.$, full symbols) and molar mass distribution $\left(\mathrm{M}_{\mathrm{w}} / \mathrm{M}_{\mathrm{n}}\right.$, hollow symbol) poly(acrylonitrile) on the monomer conversion for the acrylonitrile (AN) polymerization initiated by a low molecular weight cobalt adduct initiator $\left.\left[\mathrm{Co}(\mathrm{acac})_{2}\left(-\mathrm{CH}\left(\mathrm{OCOCH}_{3}\right) \mathrm{CH}_{2}\right)_{4}-\mathrm{R}_{0}\right)\right]$ in dimethylsulfoxide (DMSO) at $30^{\circ} \mathrm{C}(\boldsymbol{\Delta})$ and $0^{\circ} \mathrm{C}(\bullet)$. For both experiments $\left.[\mathrm{AN}] /\left[\mathrm{Co}(\mathrm{acac})_{2}\left(-\mathrm{CH}\left(\mathrm{OCOCH}_{3}\right) \mathrm{CH}_{2}\right)_{<4}-\mathrm{R}_{0}\right)\right]=$ 752 and DMSO/AN: 50/50 (v/v). The dotted line represents the theoretical dependence of the molar mass with the monomer conversion.

In both cases, the polymerization started in the absence of additional V-70 and no induction period was observed (Figure 4a), proving that the cobalt-mediated AN radical homopolymerization follows a reversible termination pathway. The DMSO most probably plays the role previously described for pyridine and water by binding to the cobalt open coordination site, thereby driving the system towards the RT process instead of DT. As expected, the kinetics were first order with respect to the monomer as assessed by the linear time dependence of the $\ln [\mathrm{M}]_{0} /[\mathrm{M}]$ function, suggesting that the number of radicals in the polymerization medium remained constant all along the polymerization. As expected, the polymerization rate is much slower at $0^{\circ} \mathrm{C}$ than at $30^{\circ} \mathrm{C}$ and the molar masses increased linearly with the monomer conversion at both temperatures. However, the molar mass is controlled much better at the lower temperature, as shown by the lower polydispersity ( $\mathrm{Mw} / \mathrm{Mn} \sim 1.15)$ (Figure $4 \mathrm{~b}$ ). In addition, the PAN molar masses were closer to the theoretical values for the experiment carried out at lower temperature, and much closer than those of the experiments carried out from V-70 and $\mathrm{Co}(\mathrm{acac})_{2}$ (compare Figure $1 \mathrm{~b}$ and Figure $4 \mathrm{~b}$ ). The high level of control obtained for the AN polymerization initiated by the cobalt(III) adduct is perfectly illustrated by the overlay of the SEC chromatograms, which are regularly shifted towards higher molar masses (Figure 5). The PAN prepared by CMRP from the cobalt(III) adduct was studied by ${ }^{1} \mathrm{H}$ NMR after treatment with TEMPO according to a previously reported procedure ${ }^{[10,13]}$ and purification by precipitation (Figure 6). Besides the typical signals of PAN ($\mathrm{CH}_{2}-\mathrm{CHCN-}$ ), the spectrum revealed the presence of signals characteristic of the very few VAc units $\left(-\mathrm{CH}_{2}-\mathrm{CHOAc}-\right)$ coming from the CMRP initiator fragment. Moreover, signals typical of methyl and methylene groups of both TEMPO at the $\omega$ chain-end and the V-70 fragment at the $\alpha$ chain-end were observed between 0.9 and $1.5 \mathrm{ppm}$.

The achievement of such a level of control for the homopolymerization of AN is only possible if the system satisfies certain conditions: the cleavage of the $\mathrm{C}-\mathrm{Co}$ bond of the initiator must be rapid at $0^{\circ} \mathrm{C}$ in DMSO, the reversible cleavage of PAN-Co bond must also be fast at $0^{\circ} \mathrm{C}$ but not faster than for the initiator, and very few irreversible termination should occur during the polymerization insured by a reversible termination equilibrium sufficiently displaced toward the dormant species.

\section{Computational investigations}

Preliminary considerations. A computational investigation was carried out on model cobalt coordination compounds, the main objective of the study being the rationalization of the effect of a strongly coordinating solvent such as DMF or DMSO on the ability of the PAN-Co(acac)2 dormant chain to grow in a controlled fashion, as well as and on the ability of the PVAc-Co(acac $)_{2}$ 


$$
\begin{aligned}
& \mathrm{M}_{\mathrm{n}}=24200 \mathrm{~g} / \mathrm{mol} \\
& \mathrm{M}_{\mathrm{w}} / \mathrm{M}_{\mathrm{n}}=1.14 \mathrm{M}_{\mathrm{n}}=2500 \mathrm{~g} / \mathrm{mol} \\
& \mathrm{M}_{\mathrm{w}} / \mathrm{M}_{\mathrm{n}}=1.16
\end{aligned}
$$

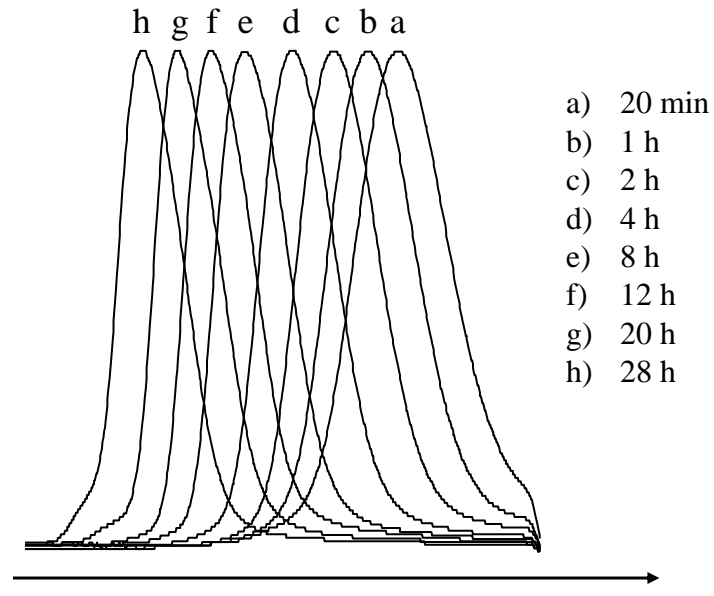

Elution time

Figure 5. Time evolution of the size exclusion chromatograms for the acrylonitrile (AN) polymerization initiated by the low molecular weight cobalt adduct $\left.\left[\mathrm{Co}(\mathrm{acac})_{2}\left(-\mathrm{CH}\left(\mathrm{OCOCH}_{3}\right) \mathrm{CH}_{2}\right)_{<4}-\mathrm{R}_{0}\right)\right]$ initiator at $0^{\circ} \mathrm{C}$ in dimethylsulfoxide. $\left.[\mathrm{AN}] /\left[\mathrm{Co}(\mathrm{acac})_{2}\left(-\mathrm{CH}\left(\mathrm{OCOCH}_{3}\right) \mathrm{CH}_{2}\right)_{<4}-\mathrm{R}_{0}\right)\right]=752 . \mathrm{M}_{\mathrm{n}}$ and $\mathrm{M}_{\mathrm{w}}$ are numberaverage and weight-average molecular weight, respectively.

dormant species to rapidly initiate the controlled polymerization of acrylonitrile. The model system consisted in a simplification of the polymer chain to the last monomer unit, the rest of the chain being replaced by an $\mathrm{H}$ atom. Thus, for instance, the $\mathrm{PAN}-\mathrm{Co}(\mathrm{acac})_{2}$ system was modeled by compound $\mathrm{CH}_{3} \mathrm{CH}(\mathrm{CN})-\mathrm{Co}(\text { acac })_{2}$.

Useful information from our recent studies on similar
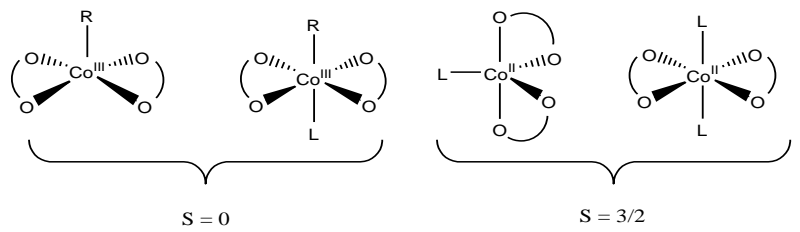

Scheme 3. Schematic geometries and spin states for the $\mathrm{Co}^{\mathrm{III}}$ and $\mathrm{Co}^{\mathrm{II}}$ complexes involved in the CMRP process.

compounds ${ }^{[12,}$ 16] includes knowledge that 5-coordinate $\mathrm{R}$ $\mathrm{Co}^{\mathrm{III}}(\mathrm{acac})_{2}$ species have a spin singlet ground state with a square pyramidal geometry ( $\mathrm{R}$ in the axial position), that 6-coordinate $\mathrm{R}$ $\mathrm{Co}^{\mathrm{III}}(\mathrm{acac})_{2}(\mathrm{~L})$ species are spin singlet with a trans-octahedral geometry, and that the 5-coordinate $\mathrm{Co}^{\mathrm{II}}(\mathrm{acac})_{2}(\mathrm{~L})$ and 6-coordinate $\mathrm{Co}^{\mathrm{II}}(\mathrm{acac})_{2}(\mathrm{~L})_{2}$ systems have a spin quartet ground state with trigonal bipyramidal ( $\mathrm{L}$ in an equatorial position) and transoctahedral geometries, respectively. These geometries are illustrated schematically in Scheme 3. Thus, there was no need to further explore other geometries and spin states for the systems described in the present contribution.

One relevant question is whether the DMSO ligand would bind the $\mathrm{Co}^{\mathrm{II}}$ and $\mathrm{Co}^{\mathrm{III}}$ compounds through the $\mathrm{O}$ or the $\mathrm{S}$ atom, since both coordination modes are adopted by this ligand. However, a search of the Cambridge Structural Database (CSD) shows that there are no structurally characterized complexes of Co containing an Sbonded DMSO ligand, whereas 25 hits were obtained for O-bonded Co(DMSO) complexes. Furthermore, searching for S-bonded DMSO complexes of any transition metals gave 250 hits (mostly for $\mathrm{Ru}, \mathrm{Rh}$, Ir, Os and Pt), of which only three featured a first row transition metal ( $\mathrm{Fe}^{\mathrm{II}}$ with $\pi$-acidic ligands in all three cases:

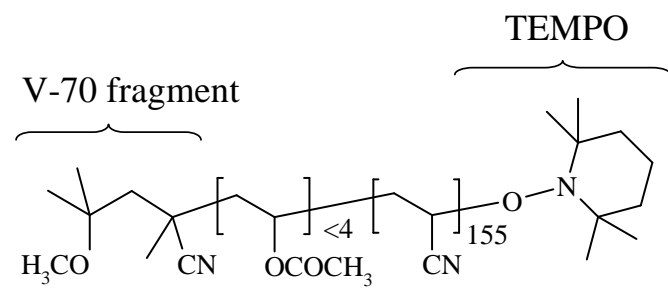

$$
\begin{aligned}
& -\mathrm{CH}_{2}-\mathrm{CH}\left(\mathrm{OCOCH} \boldsymbol{H}_{3}\right)- \\
& -\mathrm{CH}_{2}-\mathrm{CH}(\mathrm{CN})-
\end{aligned}
$$

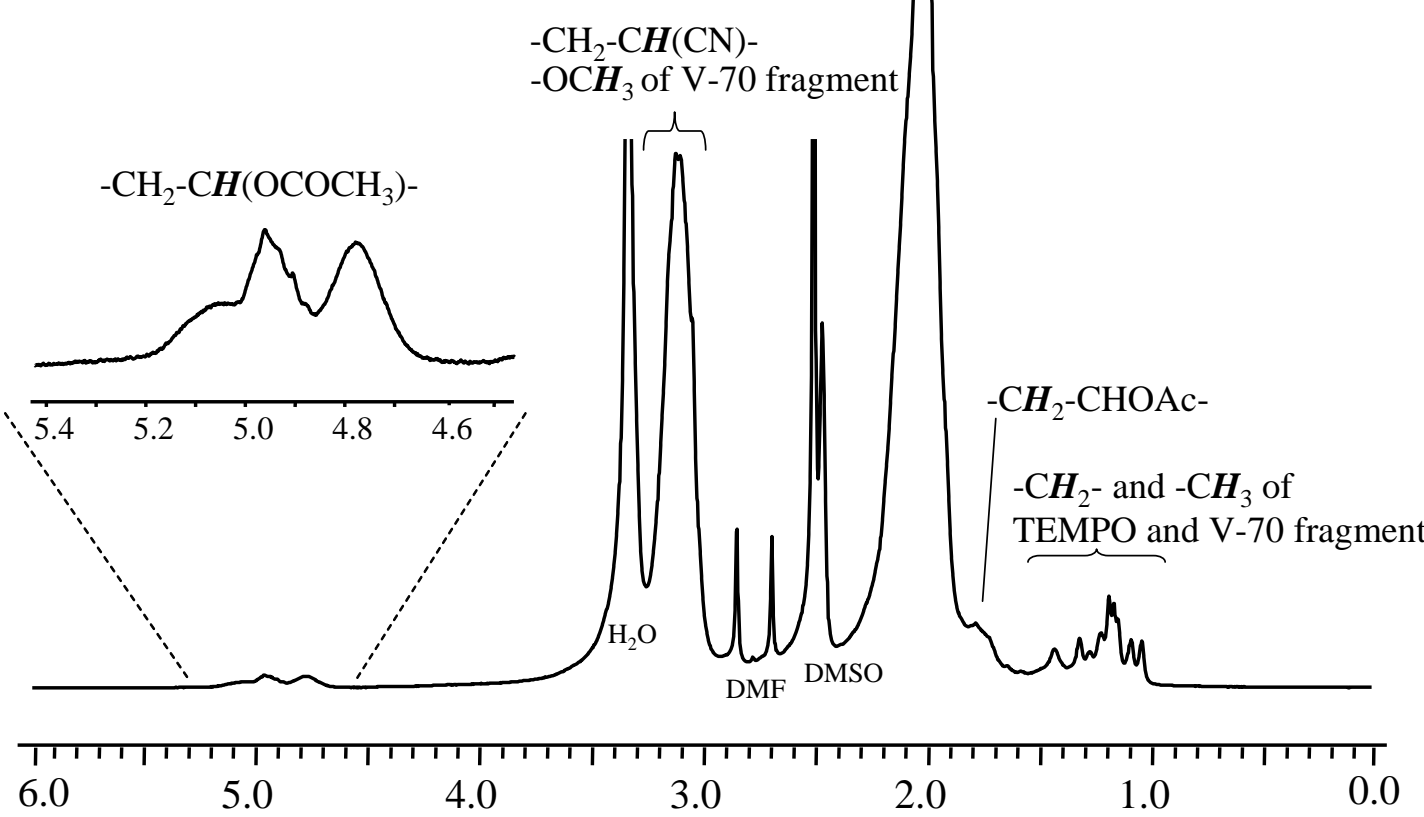

Figure 6. ${ }^{1} \mathrm{H}$ NMR spectrum for the poly(acrylonitrile) $\left(\mathrm{M}_{\mathrm{n}}=8200 \mathrm{~g} / \mathrm{mol}, \mathrm{M}_{\mathrm{w}} / \mathrm{M}_{\mathrm{n}}=1.12\right)$ prepared by initiation of acrylonitrile polymerization with a low molecular weight cobalt adduct $\left.\left[\mathrm{Co}(\mathrm{acac})_{2}\left(-\mathrm{CH}\left(\mathrm{OCOCH}_{3}\right) \mathrm{CH}_{2}\right)_{4}-\mathrm{R}_{0}\right)\right]$. 
$\left[\mathrm{Fe}(\mathrm{Pc})(\mathrm{DMSO})_{2}\right]$, where $\mathrm{Pc}=$ phtalocyanince, and two salts of $\left[\mathrm{Fe}(\mathrm{CN})_{4}(\mathrm{DMSO})\right]^{2-} \cdot{ }^{[34-36]}$ The assumption that the DMSO is Obonded to the cobalt atom was confirmed by the X-ray analysis of the $\mathrm{Co}(\mathrm{acac})_{2}(\mathrm{DMSO})_{2}$ crystals (Figure $\left.7 \mathrm{a}\right)$. The $\mathrm{X}$-ray analysis also confirmed the trans- octahedral structure of the complex. Relevant bonding parameters are listed in Table 3 and will be discussed later together with those optimized by DFT. Therefore, only O-bonded DMSO configurations were considered in our geometry optimizations.

Table 3. Relevant bond distance $(\AA)$ and angles $\left({ }^{\circ}\right)$ for the structures of compounds $\mathrm{Co}(\operatorname{acac})_{2}(\mathrm{~L})_{2} \quad(\mathrm{~L}=\mathrm{DMSO}, \mathrm{DMF})$ and comparison with the DFT optimized

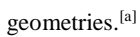

\begin{tabular}{|c|c|c|c|c|}
\hline & \multicolumn{2}{|c|}{$\mathrm{Co}(\mathrm{acac})_{2}(\mathrm{DMSO})_{2}$} & \multicolumn{2}{|c|}{$\mathrm{Co}(\mathrm{acac})_{2}(\mathrm{DMF})_{2}$} \\
\hline & X-ray & DFT & X-ray & DFT \\
\hline \multicolumn{5}{|l|}{ (a) Distances } \\
\hline $\mathrm{Co}-\mathrm{O}(\mathrm{acac})$ & $2.042(3)$ & 2.056 & $2.041(5)$ & 2.049 \\
\hline $\mathrm{Co}-\mathrm{O}(\mathrm{L})$ & $2.150(2)$ & 2.197 & $2.140(1)$ & 2.214 \\
\hline \multicolumn{5}{|l|}{ (b) Angles } \\
\hline $\mathrm{O}(\mathrm{L})-\mathrm{Co}-\mathrm{O}(\mathrm{L})$ & 180 & 179.8 & 180 & 178.1 \\
\hline $\mathrm{O}(\mathrm{acac})-\mathrm{Co}-\mathrm{O}(\mathrm{acac})(c i s)$ & $89.99(11)$ & 88.7 & $89.62(4)$ & 88.8 \\
\hline $\mathrm{O}(\mathrm{acac})-\mathrm{Co}-\mathrm{O}(\mathrm{acac})($ trans $)$ & 180 & 178.8 & 180 & 177.9 \\
\hline acac fold angle & 161.5 & 164.6 & 179.5 & 177.3 \\
\hline
\end{tabular}

${ }^{[a]}$ Average values over chemically equivalent parameters are reported.

Note that there are two possible conformations for an O-bonded DMSO ligand. The DMSO methyl substituents may be pointing away from the metal, in such a way that the $S$ lone pair points toward the coordination sphere (namely syn arrangement for the $\mathrm{S}$ lone pair and Co-O(DMS) bond, see I in Scheme 4) or viceversa (S lone pair anti to the Co-O(DMS) bond, II in Scheme 4). All 25 above-mentioned $\mathrm{Co}(\mathrm{DMSO})$ complexes retrieved from the CSD display the Me groups farther from the metal (I) and this is also the conformation adopted by compound $\mathrm{Co}(\mathrm{acac})_{2}(\mathrm{DMSO})_{2}$ (Figure 7 a), thus all starting geometries for the DFT calculations were constructed in this way.

A crystal of $\mathrm{Co}(\mathrm{acac})_{2}(\mathrm{DMF})_{2}$ was also prepared and subjected to X-Ray analysis (Figure 7b). The coordination geometry is again trans-octahedral. Selected bonding parameters are reported in Table 3. Of the two conformations that may be adopted in principle by the coordinated DMF ligand with the $\mathrm{NMe}_{2}$ group either syn or anti relative to the Co-O bond, the latter (i.e. III in Scheme 4) is less sterically hindered and is observed for all the Co(DMF) compounds known in the literature (59 hits in the CSD) and the present compound $\mathrm{Co}(\mathrm{acac})_{2}(\mathrm{DMF})_{2}$ is no exception. Noteworthy, a $\mathrm{Co}(\mathrm{acac})_{2}(\mathrm{AN})_{2}$ complex could not be formed following the same preparation procedure. Finally, we have already established that the chain-end for a PVAc-Co(acac)2, when this is obtained by bulk polymerization (namely in the absence of coordinating solvents) contains a chelating chain through the ester function of the last monomer unit, see IV in Scheme 4. ${ }^{[16]}$

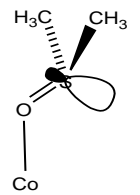

I

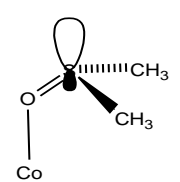

II<smiles>CN(C)COC1CCCCC1</smiles>

III

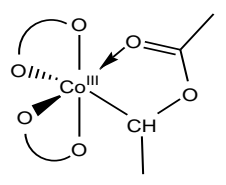

IV
Scheme 4. Coordination modes for Co(DMSO) (I and II) and Co(DMF) (III) and a model for the PVAc-Co(acac) 2 chain end (IV).
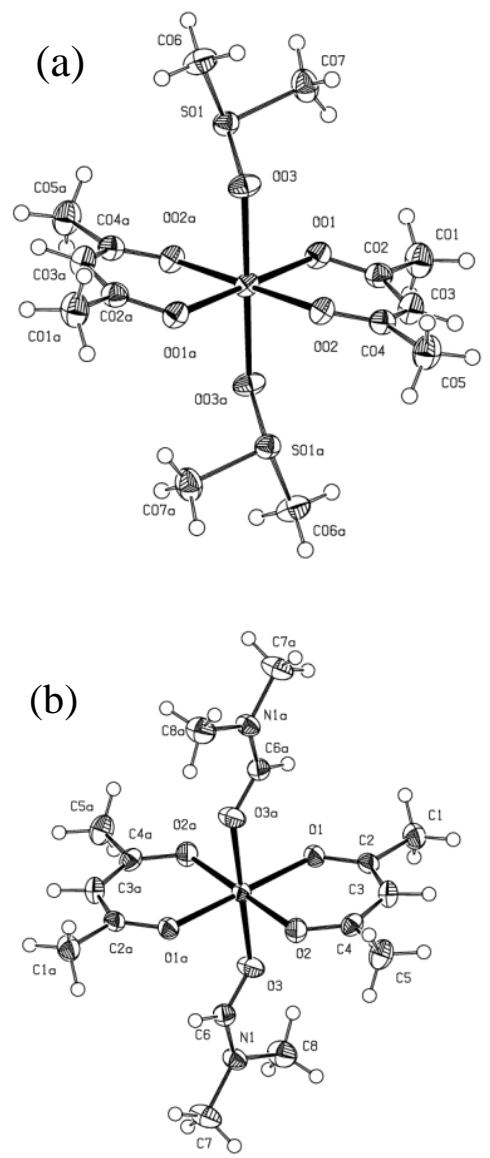

Figure 7. ORTEP views of $\mathrm{Co}(\mathrm{acac})_{2}(\mathrm{DMSO})_{2}(\mathrm{~A})$ and $\mathrm{Co}(\mathrm{acac})_{2}(\mathrm{DMF})_{2} \quad$ (B) Displacement ellipsoids are drawn at the $50 \%$ probability level.

A question of interest is whether a PAN-Co(acac) $)_{2}$ chain-end could also be stabilized by intramolecular chelation, similarly to the PVAc-Co(acac $)_{2}$ chain-end. The geometry of the acrylonitrile monomer is unsuitable for chelation via the Co-bonded monomer unit, because of the linearity of the $\mathrm{C}-\mathrm{C} \equiv \mathrm{N}$ function and the location of the nitrogen lone pair opposite to the $\mathrm{C} \equiv \mathrm{N}$ bond (sp hybridization), as shown in Scheme $5(\mathrm{~V})$. The $\pi$ electron density of this triple $\mathrm{C}-\mathrm{N}$ bond is also geometrically inaccessible. The penultimate unit may in principle coordinate the cobalt atom through the $\mathrm{CN} \pi$ electrons, see Scheme 5 (VI), but the $\mathrm{N}$ lone pair is still inaccessible because of the severe strain imposed by the linearity of the $\mathrm{Co}-\mathrm{N} \equiv \mathrm{C}-\mathrm{C}$ moiety on the 6-member cycle. We remark, however, that $\mathrm{Co}^{\mathrm{III}}$ is not sufficiently "soft" as a Lewis acid to establish strong interactions with soft donors such as the $\pi$ electron density of unsaturated organic molecules, examples of this type of interaction being unknown in stable compounds.
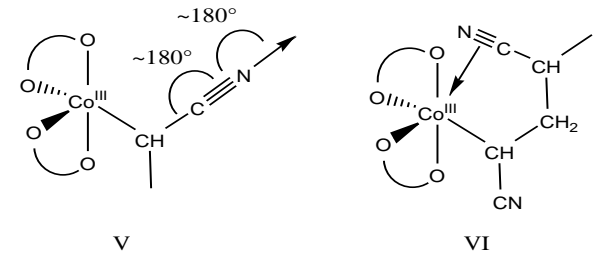

Scheme 5. Models for the PAN-Co(acac $)_{2}$ chain ends.

Coordination by the $\mathrm{CN}$ function of the third last monomer unit is a possibility. However, this coordination would not be any different from the coordination by a simple monomer molecule from 
the enthalpic point of view, while it would probably be entropically disfavoured, given the large number of degrees of freedom that would be lost in the cycle formation process. Therefore, we simply considered the coordination of a monomer molecule in our calculations. In connection with the stabilization of the dormant chain by coordination of an additional ligand, it is also crucial to evaluate the effect of this coordination on the Co-C homolytic bond strength, since it is this bond rupture that regulates the metal controlling ability on the polymerization process.

Before analyzing the results, a cautionary word must be spared about the use of DFT methods for the evaluation of bond dissociation energies where a spin state change is involved, in this case breaking the Co-C bond in a diamagnetic $\mathrm{Co}^{\mathrm{III}}$ compound to generate an organic radical $(\mathrm{S}=1 / 2)$ and a spin quartet $(\mathrm{S}=3 / 2) \mathrm{Co}^{\mathrm{II}}$ complex. The calculation of energy differences for reactions involving a spin state change is very delicately dependent on the type of functional used, and unfortunately no "rule of thumb" is available for the selection of the best functional for a specific problem. Recent theoretical work has compared different functionals for the evaluation of relative spin state energetics, including for selected cobalt complexes. ${ }^{[37,38]}$ On few occasions, the choice of the most appropriate functional could be made by comparison with experimentally available parameters, or by comparison with much higher level ab initio calculations, believed to provide a closer approximation of the experimental value. For our system, the first approach is impossible because Co-R BDEs are not experimentally available, while the second one is prohibitive given the relative complexity of the systems. Thus, the calculations were carried out using two different functionals, the commonly employed B3LYP functional and a modified B3PW91 functional, termed B3PW91* (see Computational Details section). In essence, both functionals are part of a general family of "correlated" functionals, namely taking into account the effect of electronic correlation, but the B3LYP was found in many instances to overestimate the amount of exact exchange, thereby overestimating the stability of the higher spin states. Reducing the exact exchange admixture biases the results in favour of the lower spin states. ${ }^{[39]}$ The use of B3PW91* was shown to provide better results for reaction energetics involving iron compounds where changes of spin are involved. ${ }^{[40-42]}$ The B3PW91* calculations were carried out as single point calculations on the B3LYP-optimized geometries, since
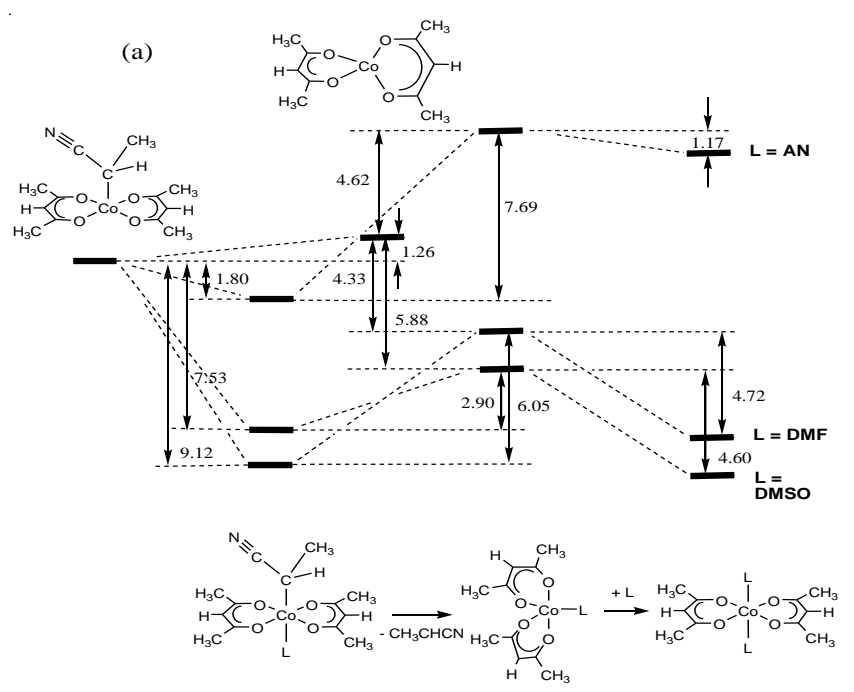

reoptimization is believed to lead to negligible structural changes and consequently to negligible energy differences. This was verified for $\mathrm{Co}(\mathrm{acac})_{2}$, where geometry reoptimization led to an energy change of $<0.1 \mathrm{kcal} \mathrm{mol}^{-1}$.

All optimized geometries are provided as xyz files in the Supporting Information. The optmized structures of $\mathrm{Co}(\mathrm{acac})_{2}(\mathrm{~L})_{2}$ for $\mathrm{L}=\mathrm{DMSO}$ and DMF are compared with the experimentally determined ones in Table 3. The DFT methodology is notoriously providing longer distances relative to the experiment, especially for dative type bonds. This is also observed here, the calculated Co$\mathrm{O}$ (acac) bonds being much closer to the experimental values than the calculated $\mathrm{Co}-\mathrm{O}(\mathrm{L})$ bonds. There is, however, good agreement in general between the observed and calculated geometries, and these are very similar to each other upon going from DMSO to DMF. Both X-ray structures have the metal atom located on an inversion center, thus all trans angles are strictly linear by symmetry and the calculated values (with no symmetry-imposed restriction) fall very close to linearity. The most significant difference between the two compounds is the fold angle of the $\mathrm{M}(\mathrm{acac})$ chelate moiety, namely the angle between the O-Co-O plane and the acac ligand plane. It is significantly smaller than $180^{\circ}$ for the DMSO adduct and much less so for the DMF adduct, for unclear reasons. This observed structural feature is also reproduced quite well by the calculations, further testifying about the suitability of the computational level. Additional geometrical features will not be discussed. The remainder of this section deals only with bond energy arguments.

Models for the (acac) ${ }_{2}$ Co-PAN dormant species in AN homopolymerization. The results of the calculations involving the $\mathrm{CH}(\mathrm{CN}) \mathrm{CH}_{3}$ radical, used as a model of the PAN growing chain, are shown in Figure 8. Part (a) shows the results obtained with B3LYP while those obtained with B3PW91* are collected in part (b). As expected, the two functionals yield very different Co-C BDE's, B3PW91* yielding greater relative stability for the singlet alkylcobalt(III) complexes and consequently greater Co-C BDEs (by ca. $6.5 \mathrm{kcal}$ mol-1 for the R-Co(acac $)_{2}(\mathrm{~L})$ species, $5.5 \mathrm{kcal}$ mol-1 for the L-free system), whereas nearly identical results are obtained for the processes involving no spin state change (ligand dissociations from either spin quartet $\mathrm{CO}^{\mathrm{II}}$ or spin singlet $\mathrm{Co}^{\mathrm{III}}$ ). The strength of the $(\mathrm{acac})_{2} \mathrm{Co}-\mathrm{CH}(\mathrm{CN}) \mathrm{CH}_{3}$ bond can be compared with those of

(b)
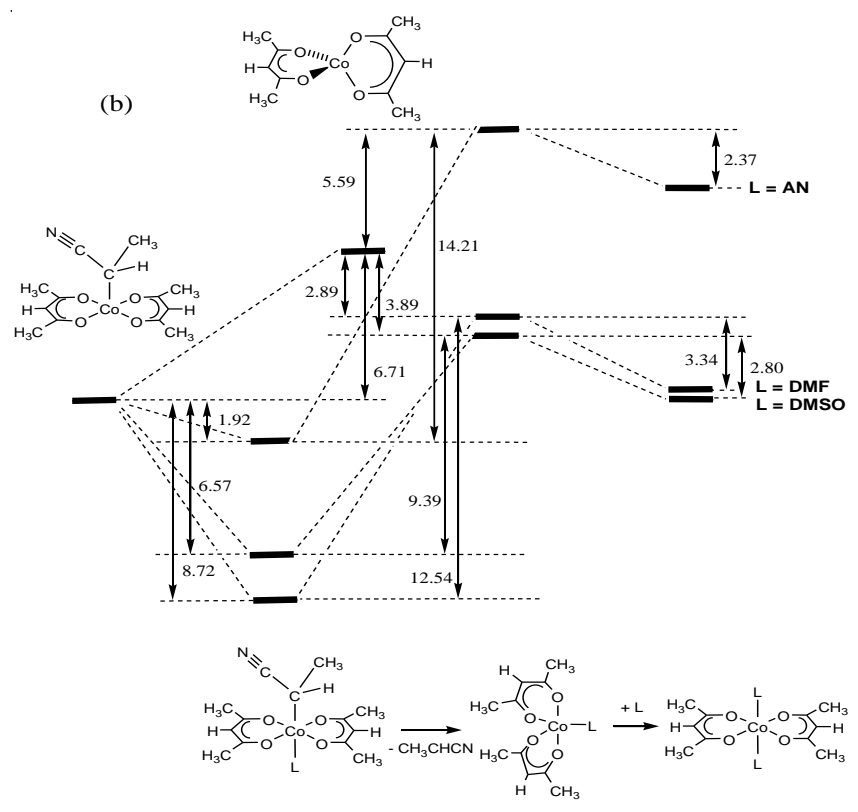

Figure 8. Energy diagram obtained with the B3LYP (a) or B3PW91* (b) functional for the Co-C homolytic bond cleavage and subsequent $\mathrm{L}$ addition in (acac) ${ }_{2}(\mathrm{~L}) \mathrm{Co}-\mathrm{CH}(\mathrm{CN}) \mathrm{CH} 3$ $\left(\mathrm{L}=\right.$ nothing, AN, DMF, DMSO). The values shown are relative enthalpies in $\mathrm{kcal}_{\mathrm{mol}}{ }^{-1}$. 
other (acac) 2 Co-R bonds only at the B3LYP level, since this was the only functional used in previous calculations. The BDE varies in the order $\mathrm{Me}(14.55)>\mathrm{CH}\left(\mathrm{OCH}_{3}\right) \mathrm{CH}_{3}(8.45)>\mathrm{CH}\left(\mathrm{OOCCH}_{3}\right) \mathrm{CH}_{3}$ (5.73) > $\mathrm{CH}(\mathrm{CN}) \mathrm{CH}_{3}$ (1.26) > $\mathrm{CH}\left(\mathrm{COOCH}_{3}\right) \mathrm{CH}_{3}$ (-1.50) > $\mathrm{C}\left(\mathrm{CH}_{3}\right)_{2}(\mathrm{CN})(-5.52){ }^{[12,16]}$ The trend is consistent with expectations on the basis of known stabilization effects and qualitatively parallels that reported for alkyl halides and dithiocarboxylates. ${ }^{[43,44]}$ In particular, it shows that the (acac) ${ }_{2} \mathrm{Co}-\mathrm{CH}(\mathrm{CN}) \mathrm{CH}_{3}$ bond is relatively weak, consistent with the stabilized nature and low reactivity of the $\mathrm{CH}(\mathrm{CN}) \mathrm{CH}_{3}$ radical.

The BDE value obtained for this bond with BPW91* is greater, $6.71 \mathrm{kcal} \mathrm{mol}^{-1}$. As mentioned above, it is not possible to assess which of these values is closer to the true BDE. However, we must also underline that these are enthalpy values, whereas bond dissociation equilibria of relevance to controlled polymerization are based on free energy differences. The entropic contribution could be also estimated by the calculations, but only in the gas phase. For all reactions that increase the number of independent molecules by one unit, such as the $\mathrm{Co}^{\mathrm{III}}-\mathrm{R}$ homolytic bond breaking (but also the $\mathrm{L}$ dissociation from the $\mathrm{Co}^{\mathrm{III}}$ and $\mathrm{Co}^{\mathrm{II}}$ systems), the $-\mathrm{T} \Delta \mathrm{S}$ term is ca. $-10 \mathrm{kcal} \mathrm{mol}^{-1}$ in the gas phase at room temperature, the most important contribution being the generation of three new translational modes. These modes, however, are quenched to a large extent in condensed phases. Thus, the application of the computational results to the polymerization process in a condensed phase will always be, at any rate, qualitative. The BPW91* results are probably providing a better estimate of the $\mathrm{Co}^{\mathrm{III}}-\mathrm{R}$ bond strength than the B3LYP results, because the latter would not easily account for the ability of $\mathrm{Co}^{\mathrm{II}}$ to efficiently trap the growing PAN radical chain and control the polymerization. The main purpose of this study is to assess the tuning effect of the neutral ligand $\mathrm{L}$ on the metal controlling ability. Thus, we shall mainly comment on how ligand coordination affects the relative stability of the $\mathrm{Co}^{\mathrm{III}}$ and $\mathrm{Co}^{\mathrm{II}}$ systems, with greater emphasis on the B3PW91* results.

At each oxidation state level, ligand coordination does not change the spin state of the system and both functionals afford similar values for the enthalpy change. The coordination of a neutral donor $(\mathrm{L})$ to the 6 th site of the pseudo-octahedral geometry of the $\mathrm{Co}^{\mathrm{III}}$ center stabilizes the system as expected. The $\mathrm{Co}^{\mathrm{III}}-\mathrm{L}$ bond strength follows the order AN < DMSO < DMF at both functional levels. The very small bond energy for AN, combined with the unfavourable entropy for this step, means that (acac) $)_{2} \mathrm{Co}-$ $\mathrm{CH}\left(\mathrm{CH}_{3}\right) \mathrm{CN}$ is probably the dominant species in solution, and not the solvent adduct (acac) $)_{2} \mathrm{Co}(\mathrm{AN})-\mathrm{CH}\left(\mathrm{CH}_{3}\right) \mathrm{CN}$. The bond energy for DMF and DMSO is much larger, so in those cases the octahedral ligand adduct should dominate.

Ligand coordination to $\mathrm{Co}(\mathrm{acac})_{2}$ has a different effect depending on the coordination environment. On going from 5coordinate $\mathrm{Co}(\mathrm{acac})_{2} \mathrm{~L}$ to 6-coordinate $\mathrm{Co}(\mathrm{acac})_{2} \mathrm{~L}_{2}$, the ligand addition is also clearly exothermic for all ligands, following the order AN < DMSO DMF, but not as much as for the addition to singlet $\mathrm{Co}^{\mathrm{III}}$. This difference correlates with the orbital occupation: the ligand donates its electron pair to a half-occupied orbital in the $\mathrm{Co}^{\mathrm{II}}$ complex, in contrast to an empty orbital in the $\mathrm{Co}^{\mathrm{III}}$ complex. On the other hand, on going from 4-coordinate $\mathrm{Co}(\mathrm{acac})_{2}$ to 5coordinate $\mathrm{Co}(\mathrm{acac})_{2} \mathrm{~L}$, the effect is destabilizing for $\mathrm{AN}$ and stabilizing for DMF and DMSO. This shows that there is an additional energy penalty to pay for taking the $\mathrm{Co}^{\mathrm{II}}$ from the tetrahedral configuration of $\mathrm{Co}(\mathrm{acac})_{2}$ to the trigonal bipyramidal configuration. This penalty is reflected into a slight $\mathrm{BDE}$ increase for the $\mathrm{Co}-\mathrm{CH}(\mathrm{CN}) \mathrm{CH}_{3}$ bond in the presence of donor ligands (3-7

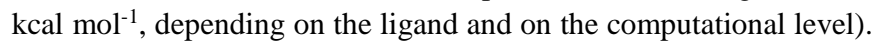

This BDE increase is smallest for $\mathrm{L}=\mathrm{DMSO}$, intermediate for $\mathrm{L}=$ $\mathrm{DMF}$ and largest for $\mathrm{L}=\mathrm{AN}$, and appears to correlate with the steric bulk of L. This computation result is consistent with the fact that $\mathrm{Co}(\mathrm{acac})_{2}(\mathrm{AN})_{2}$ crystals could not be obtained following the procedure established for $\mathrm{Co}(\mathrm{acac})_{2}(\mathrm{DMSO})_{2}$ and $\mathrm{Co}(\mathrm{acac})_{2}(\mathrm{DMF})_{2}$ (cf. above).

When considering the addition of $\mathrm{L}$, leading first from $\mathrm{Co}(\mathrm{acac})_{2}$ to $\mathrm{Co}(\mathrm{acac})_{2}(\mathrm{~L})$, and then from $\mathrm{Co}(\mathrm{acac})_{2}(\mathrm{~L})$ to $\mathrm{Co}(\mathrm{acac})_{2}(\mathrm{~L})_{2}$, the relative energy changes for each step, in $\mathrm{kcal} \mathrm{mol}^{-1}$, at the B3PW91* (B3LYP) are: for AN, 5.59 (4.62), -2.37 (-1.17); for DMF, -2.89 (4.33), -3.34 (-4.72); for DMSO, -3.89 (-5.88), -2.80 (-4.60). These trends can be rationalized with an increasing donor power in the order AN $<$ DMF $<$ DMSO and with an increasing steric bulk in the same order. Thus, for the smaller AN ligand the second addition is much more favorable than the first one whereas for the bulkier DMSO ligand, in spite of the greater energy penalty in the first addition step, the second addition is less favorable than the first one. Applying once again qualitative considerations that include entropic effects, the dominant form of $\mathrm{Co}(\mathrm{acac})_{2}$ should be the 6-coordinate bis-adduct in DMF and DMSO solutions (and indeed the compound crystallizes in this form, vide supra) and the tetrahedral ligand-free systems in AN. Indeed, previous NMR studies have evidenced equilibria between $\mathrm{Co}(\mathrm{acac})_{2}$ and ligand adducts for $\mathrm{L}=\mathrm{NEt}_{3}$ and py, for which the bond energy was calculated (B3LYP) as 6-7 kcal $\mathrm{mol}^{-1} \cdot{ }^{[12]}$

Given that, for $\mathrm{L}=\mathrm{AN}$, rupture of the $(\mathrm{acac})_{2}(\mathrm{~L}) \mathrm{Co}-$ $\mathrm{CH}(\mathrm{CN}) \mathrm{CH}_{3}$ would lead to an endothermic situation relative to the separate $\mathrm{Co}(\mathrm{acac})_{2}$ and $\mathrm{L}$, the homolytic bond breaking process is then presumably concerted with $\mathrm{L}$ dissociation (equation 2 or 2'). As stated above, entropy considerations indicate that the dominant $\mathrm{Co}^{\text {III }}$ form in solution may be 5-coordinate. Note that the stabilization of $\mathrm{Co}(\mathrm{acac})_{2}(\mathrm{AN})$ by an additional $\mathrm{AN}$ molecule yields a situation that is still endothermic relative to tetrahedral $\mathrm{Co}(\mathrm{acac})_{2}$. These equations model the radical controlling equilibrium when the CMRP of AN is carried out in a non coordinating solvent such as anisole, the only donor ligand available for stabilization being AN itself. For $\mathrm{L}=\mathrm{DMF}$ and DMSO, on the other hand, the 5coordinate $\mathrm{Co}(\mathrm{acac})_{2}(\mathrm{~L})$ complex is exothermic relative to the separated $\mathrm{Co}(\mathrm{acac})_{2}$ and $\mathrm{L}$ and is further stabilized by coordination of a second L molecule (to a greater extent at the B3LYP level). Thus, the radical generation process can be summarized by equation 3.

$$
\begin{gathered}
(\text { acac })_{2} \mathrm{Co}-\mathrm{CH}\left(\mathrm{CH}_{3}\right) \mathrm{CN} \rightarrow \mathrm{Co}(\mathrm{acac})_{2}+\cdot \mathrm{CH}\left(\mathrm{CH}_{3}\right) \mathrm{CN} \\
(\text { acac })_{2} \mathrm{Co}(\mathrm{AN})-\mathrm{CH}\left(\mathrm{CH}_{3}\right) \mathrm{CN} \rightarrow \mathrm{Co}(\mathrm{acac})_{2} \\
+\mathrm{AN}+\cdot \mathrm{CH}\left(\mathrm{CH}_{3}\right) \mathrm{CN} \\
(\text { acac })_{2}(\mathrm{~L}) \mathrm{Co}-\mathrm{CH}\left(\mathrm{CH}_{3}\right) \mathrm{CN}+\mathrm{L} \rightarrow \mathrm{Co}(\mathrm{acac})_{2}(\mathrm{~L})_{2} \\
+\cdot \mathrm{CH}\left(\mathrm{CH}_{3}\right) \mathrm{CN}
\end{gathered}
$$$$
\text { ( } \mathrm{L}=\mathrm{DMF}, \mathrm{DMSO})
$$

The effective polymerization rate depends linearly on the radical propagation rate constant (a kinetic factor), which is the same in all cases, and on the equilibrium constant of the reversible radical generation process (a thermodynamic factor), which depends on $\mathrm{L}$. The reaction enthalpies of equations 2 or 2' (for $\mathrm{AN}$ ), and 3 (for DMF and DMSO) are as follows (B3PW91* values, with B3LYP values in parentheses): AN, 6.71 (1.26) for eq. 2 or 8.63 (3.06) for eq. 2', DMF 9.20 (1.34), DMSO 6.59 (-1.70). The enthalpic term being relatively close to each other with and without ligand, it is necessary to take into account the entropic factor $(-T \Delta S)$ to evaluate the impact of the ligand on the reversible dissociation equilibrium leading to radical formation. While the dissociation reaction 2' (and 
2 to an even greater extent) is characterized by a negative $-\mathrm{T} \Delta \mathrm{S}$ term, reaction 3 is approximately isoentropic. Thus, the calculations predict that reactions 2 and 2' are more favored than reaction 3 and, consequently, that $\mathrm{Co}(\mathrm{acac})_{2}$ is a better trap for the PAN growing radical chain in DMSO or DMF relative to non coordinating solvents (anisole or AN). At the quantitative level, as discussed above, the B3PW31* results are probably closer to the reality. The B3LYP results cannot be quantitatively correct for the simple reason that they would not predict the ability of the $\mathrm{Co}^{\mathrm{II}}$ system to trap free radicals, since the spin trap would be more stable than the dormant chain for $\mathrm{L}=\mathrm{DMSO}$ and the $-\mathrm{T} \Delta \mathrm{S}$ term would further disfavor the trapping process. On the other hand, the experiment shows that $\mathrm{Co}(\mathrm{acac})_{2}$ is quite capable of insuring a controlled growth of PAN by the RT mechanism in the DMSO solvent.

To conclude this part, the (acac) ${ }_{2} \mathrm{Co}-\mathrm{PAN}+\mathrm{L}$ system shows two major differences relative to the previously studied ${ }^{[12]}$ (acac) $)_{2} \mathrm{Co}-$ $\mathrm{CH}_{3}+\mathrm{L}$ model system. The first one is a significant modulation of the Co ${ }^{I I I}$-PAN homolytic bond strength by $\mathrm{L}$ coordination $(\mathrm{L}=\mathrm{AN}$, DMF, DMSO), whereas the strength of the $\mathrm{Co}^{\mathrm{III}}-\mathrm{CH}_{3}$ bond resulted approximately insensitive to axial $\mathrm{L}$ bonding $(\Delta \mathrm{E}$ in $\mathrm{kcal} / \mathrm{mol}$ at the B3LYP level: $\mathrm{L}=\mathrm{VAc}, 21.82 ; \mathrm{NMe}_{3}, 20.65 ; \mathrm{py}, 21.83 ; \mathrm{H}_{2} \mathrm{O}, 22.65$; $\mathrm{NH} 3,21.80)$. The intrinsically weaker nature of the Co$\mathrm{CH}\left(\mathrm{CH}_{3}\right)(\mathrm{CN})$ bond relative to the $\mathrm{Co}-\mathrm{CH}_{3}$ bond is probably at the origin of this effect. Amongst AN, DMF and DMSO, the latter has the strongest labilizing effect, due to a larger $\Delta(\Delta \mathrm{H})=\left[\mathrm{BDE}\left(\mathrm{Co}^{\mathrm{II}}-\mathrm{L}\right)\right.$ $\left.-\mathrm{BDE}\left(\mathrm{Co}^{\mathrm{III}}-\mathrm{L}\right)\right]$. The second difference concerns the strength of the $\mathrm{Co}^{\mathrm{II}}-\mathrm{L}$ interaction. Whereas py and $\mathrm{H}_{2} \mathrm{O}$ were found to be very good ligands for $\mathrm{Co}^{\mathrm{II}}$, yielding energy gains in excess of $10 \mathrm{kcal} / \mathrm{mol}$ on going from $\mathrm{Co}(\mathrm{acac})_{2}(\mathrm{~L})$ to $\mathrm{Co}(\mathrm{acac})_{2}(\mathrm{~L})_{2},{ }^{[12]}$ the stabilization provided by AN, DMF and DMSO is much more modest.

Models for the (acac) $)_{2} \mathrm{Co}-\mathrm{PVAc}$ as macroinitiator in AN homopolymerization. Once verified that the homolytic bond cleavage of $(\mathrm{L})(\mathrm{acac})_{2} \mathrm{Co}-\mathrm{PAN}$ is consistent with control of the AN polymerization by the reversible termination mechanism in the DMSO solvent, the next experimental phenomenon to be addressed is the solvent effect on the ability of the (acac) 2 Co-PVAc macroinitiator to efficiently initiate the CRP of AN. Figure 9 summarizes the computational results at the B3LYP (a) and B3WP91* (b) levels for the overall process. On going from left to right, the (acac) $)_{2} \mathrm{Co}\left\{\kappa^{2}: C, O-\mathrm{CH}\left(\mathrm{CH}_{3}\right) \mathrm{OCOCH}_{3}\right\}$ complex, which models the resting state of the growing (acac) $)_{2} \mathrm{Co}-\mathrm{PVAc}$ chain, first opens the acetate chelate freeing up a coordination site on $\mathrm{Co}^{\mathrm{III}}$, which is saturated by L coordination. Like in the case of the $\mathrm{L}$ addition to the (acac) ${ }_{2} \mathrm{Co}-\mathrm{PAN}$ model, coordination by AN provides very little stabilization (in fact, the interaction is even slightly endothermic at the B3LYP level), whereas the DMF and DMSO additions are more exothermic. The next step is the homolytic rupture of the $\mathrm{Co}^{\mathrm{III}}-\mathrm{CH}\left(\mathrm{CH}_{3}\right) \mathrm{OOCCH}_{3}$ bond. Again, the $\mathrm{Co}^{\mathrm{III}}-\mathrm{R}$ $\mathrm{BDE}$ is significantly greater at the B3PW91* level relative to B3LYP (by ca. 6 kcal mol-1 for the (L)(acac) $)_{2} \mathrm{Co}$ $\mathrm{CH}\left(\mathrm{CH}_{3}\right) \mathrm{OOCCH}_{3}$ species and $4.2 \mathrm{kcal}$ mol-1 for the L-free complex). Like in the case of the $\mathrm{Co}^{\mathrm{III}}-\mathrm{CH}\left(\mathrm{CH}_{3}\right) \mathrm{CN}$ bond, the BDE depends on the nature of $\mathrm{L}$, increasing in the order DMSO $<$ DMF < $\mathrm{AN}$, but the effect of $\mathrm{L}$ coordination on the $\mathrm{Co}^{\mathrm{III}}-\mathrm{R} \mathrm{BDE}$ is less for $\mathrm{R}$ $=\mathrm{CH}\left(\mathrm{CH}_{3}\right) \mathrm{OOCCH}_{3}$ than for $\mathrm{CH}\left(\mathrm{CH}_{3}\right) \mathrm{CN}$. The coordination of DMSO, in fact, has almost no effect at either computational level. After the radical dissociation, the residual $\operatorname{Co}(\mathrm{acac})_{2}(\mathrm{~L})$ complex is trapped by a second $\mathrm{L}$ molecule to yield $\operatorname{Co}(\operatorname{acac})_{2}(\mathrm{~L})_{2}$. The energetic of this process has already been presented in the above section, but is repeated in Figure 9 for clarity. Notably, as already discussed above, $\mathrm{Co}(\mathrm{acac})_{2}(\mathrm{AN})$ and $\mathrm{Co}(\mathrm{acac})_{2}(\mathrm{AN})_{2}$ are endo- thermic relative to $\mathrm{Co}(\mathrm{acac})_{2}+\mathrm{AN}$. Therefore, the $\mathrm{Co}^{\mathrm{III}}$ $\mathrm{CH}\left(\mathrm{CH}_{3}\right) \mathrm{OOCCH}_{3}$ homolytic splitting can be represented by equations 4 (or 4') and 5, depending on the nature of L. After the formation of $\mathrm{Co}(\mathrm{acac})_{2}$ (in non coordinating solvents) or $\mathrm{Co}(\mathrm{acac})_{2-}$ $(\mathrm{L})_{2}$ (in DMF or DMSO), the latter is available to trap the growing PAN radical which is in turn generated by AN addition to the PVAc radical (the reverse of the activation of the $(\mathrm{L})(\mathrm{acac})_{2} \mathrm{Co}-\mathrm{PAN}$ model systems in Figure 8). We underline that Figure 9 compares directly the activation energetics of the two model systems of the dormant chains, PAN-Co(acac $)_{2}$ and PVAc-Co(acac) $)_{2}$, relative to the common spin trap $\mathrm{Co}(\mathrm{acac})_{2}$ (in non-coordinating solvents) or $\mathrm{Co}(\mathrm{acac})_{2}(\mathrm{~L})_{2}$ (in DMF or DMSO. Therefore, the energy diagram is normalized relative to the monomer addition step (i.e. the conversion of the PAN radical to the PVAc radical).

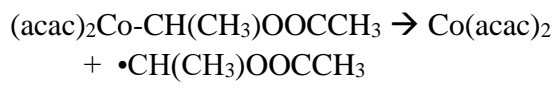

$(\text { acac })_{2}(\mathrm{AN}) \mathrm{Co}-\mathrm{CH}\left(\mathrm{CH}_{3}\right) \mathrm{OOCCH}_{3} \rightarrow \mathrm{Co}(\mathrm{acac})_{2}$ $+\mathrm{AN}+\cdot \cdot \mathrm{CH}\left(\mathrm{CH}_{3}\right) \mathrm{OOCCH}_{3}$

$(\operatorname{acac})_{2}(\mathrm{~L}) \mathrm{Co}-\mathrm{CH}\left(\mathrm{CH}_{3}\right) \mathrm{OOCCH}_{3}+\mathrm{L} \rightarrow \mathrm{Co}(\mathrm{acac})_{2}(\mathrm{~L})_{2}$ $+\cdot \mathrm{CH}\left(\mathrm{CH}_{3}\right) \mathrm{OOCCH}_{3}$

(L = DMF, DMSO)

The efficiency of this activation process can be estimated on the basis of the enthalpy difference between the starting dormant species and the stable form of the $\mathrm{Co}^{\mathrm{II}}$ radical trapping species (the -T $\Delta \mathrm{S}$ term is approximately equivalent on going from the PAN mode to the PVAc model, so long as we compare processes in the same solvent). The starting dormant species will be the (acac) ${ }_{2} \mathrm{Co}-$ PVAc complex with a chelated $\left(\kappa^{2}: C, O\right)$ chain-end in non coordinating solvents, because the AN monomer does not have sufficient coordinating power to open the chelate and form the putative (AN)(acac) 2 Co-PVAc adduct. The same may also be true in DMF and DMSO, since the solvent binding energy is similar to the energy associated to chelation of the terminal VAc unit (binding of the carbonyl function) and the entropy term disfavors solvent binding. However, if this term does not play a major role in the condensed phase, the dominant species may be the solvent adduct (L)(acac) $)_{2}$ Co-PVAc, especially in DMF. The stable form of the $\mathrm{Co}^{\mathrm{II}}$ radical trapping species, as shown above, is $\mathrm{Co}(\mathrm{acac})_{2}$ in non coordinating solvents and $\mathrm{Co}(\mathrm{acac})_{2}(\mathrm{~L})_{2}$ in DMF or DMSO. The enthalpy change for activation of the PVAc-Co(acac) $)_{2}$ dormant chain in the different solvents is (B3PW91* values, with B3LYP

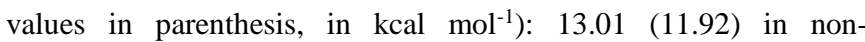
coordinating solvents $(\mathrm{L}=\mathrm{AN}) ; 10.77$ (3.51) for $\mathrm{L}=\mathrm{DMF}$; and 7.08 $(-0.12)$ for $\mathrm{L}=$ DMSO. With both functionals, the aptitude of the Co-terminated PVAc dormant chain to be activated follows the same order as the Co-terminated PAN chain as a function of L: AN $<$ DMF < DMSO. Once again, the B3LYP values are probably not providing a quantitatively realistic picture, because the R$\mathrm{Co}(\mathrm{acac})_{2}(\mathrm{~L})$ species are not sufficiently stabilized relative to $\mathrm{Co}(\mathrm{acac}) 2(\mathrm{~L}) 2$.

These results qualitatively agree with the observed phenomena and provide a basis for their interpretation. The Co-terminated PVAc species is not an efficient macroinitiator for the AN polymerization in a non-coordinating solvent (e.g. anisole). Under these conditions, such species generate slowly PVAc• radicals in the AN homopolymerization ${ }^{[21]}$ due to the intramolecular complexation $\left(\kappa^{2}: \mathrm{C}, \mathrm{O}\right)$ which stabilizes the Co-C bond. ${ }^{[16]}$ On the other hand, the same species controls the homopolymerization of VAc by reversible termination in the presence of neutral donor ligands $\left(\mathrm{NEt}_{3}, \mathrm{py}\right.$, $\left.\mathrm{H}_{2} \mathrm{O}\right)^{[12,16]}$ and initiates the controlled (by reversible termination) 


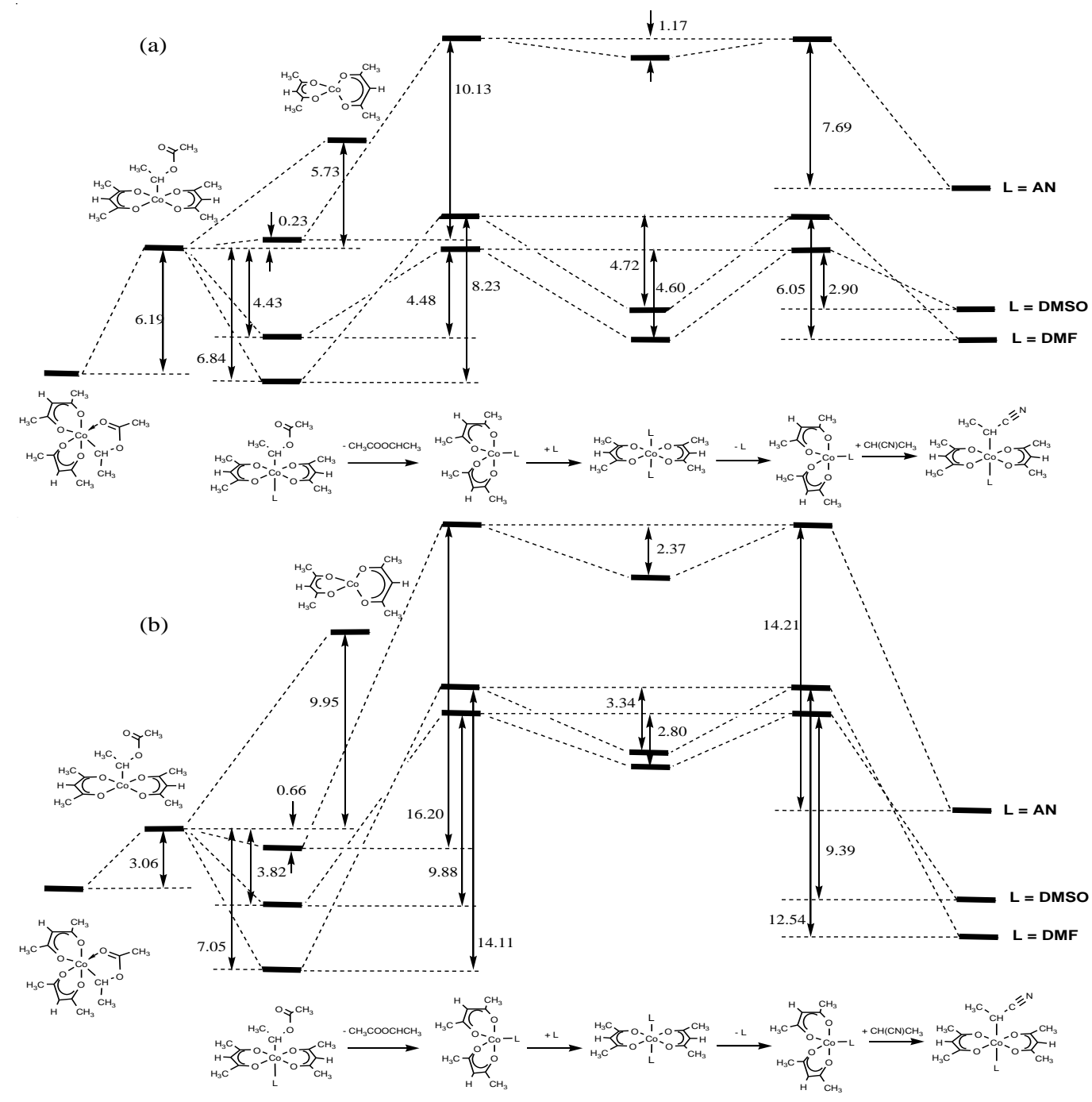

Figure 9. Energy diagram obtained with the B3LYP (a) or B3PW91* (b) functional for the Co-C homolytic bond cleavage in (acac) 2 Co$\mathrm{CH}\left(\mathrm{CH}_{3}\right)\left(\mathrm{OCOCH}_{3}\right)$ and subsequent trapping of the $\mathrm{CH}(\mathrm{CN}) \mathrm{CH}_{3}$ radical in the presence of different neutral donors $(\mathrm{L}=\mathrm{AN}$, DMF, DMSO). The values shown are relative enthalpies in $\mathrm{kcal} \mathrm{mol}^{-1}$.

AN polymerization in $\mathrm{DMF}^{[21]}$ and in DMSO (this work). This is made possible by the subtle stabilization of the intermediate $\mathrm{Co}^{\text {II }}$ complex by $\mathrm{L}$ addition. In spite of the weaker $\mathrm{Co}^{\text {III }}-\mathrm{PAN}$ bond relative to the $\mathrm{Co}^{\mathrm{III}}$-VOAc bond (estimated as $0.5-2.5 \mathrm{kcal} \mathrm{mol}^{-1}$ depending on the nature of $\mathrm{L}$ and the computational level), this bond still remains sufficiently strong to insure an efficient trapping process and therefore a good level of control. The initiation by the (acac) ${ }_{2}$ Co-PVAc macroinitiator is predicted by the calculation to be faster in DMSO, in agreement with the experimental result.

\section{Conclusion}

Because of the moderate solubility of the poly(acrylonitrile) in $\mathrm{DMF}$ at room temperature, the homopolymerization of $\mathrm{AN}$ by CMRP was investigated in DMSO. Typically, the AN polymerization initiated by $\mathrm{V}-70$ in the presence of $\mathrm{Co}(\mathrm{acac})_{2}$ presented clear evidences that polymer chains are growing in a controlled fashion, such as increase of the molar mass with the monomer conversion and rather low molar mass distribution ( 1.4). However, a deviation from the linearity was observed for the dependence of the molar mass with the conversion. Under these conditions, the number of chains involved in the CMRP process increases along the polymerization due to the slow V-70 decomposition leading to a discrepancy between experimental and theoretical molar masses calculated considering the $[\mathrm{AN}]_{0} /[\mathrm{Co}]_{0}$ ratio and the broadening of the molar mass distribution. This limitation was circumvent by using organocobalt(III) adduct as initiator at $0^{\circ} \mathrm{C}$ in DMSO for the acrylonitrile polymerization. In this case, all the chains were initiated at the same time and their number, determined by initiator concentration, remained constant all along the process allowing formation of poly(acrylonitrile) with predictable molar masses and molar mass distribution as low as 1.1 .

DFT calculations, associated with X-ray analyses, confirmed that the coordination of the cobalt complex by the solvent molecules (DMSO and DMF) changes its reactivity. As a rule, the $\mathrm{Co}-\mathrm{C}$ bond is weaker when the metal is coordinated by DMF and DMSO but it remains sufficiently strong to ensure the control of the AN polymerization. Moreover, it was demonstrated that this labilizing effect promoted by DMF and DMSO (especially the latter) was responsible for the fast initiation of the AN block from a PVAc-Co macroinitiator allowing the formation of well-defined PVAc- $b$-PAN copolymers.

\section{Experimental Section}

Materials. Vinyl acetate (>99\%, Aldrich) and acrylonitrile (>99\%, Aldrich) were dried over calcium hydride, degassed by several freeze-thawing cycles before being distilled under reduced pressure and stored under argon. Dimethylsulfoxide (DMSO) was dried over calcium hydride before being distilled under reduced pressure and stored under argon. Dimethylformamide (DMF) and dichloromethane $\left(\mathrm{CH}_{2} \mathrm{Cl}_{2}\right)$ were dried over molecular sieves and degassed by bubbling argon for 30 minutes. 2,2'-Azo-bis-(4methoxy-2,4-dimethyl valeronitrile) (V-70) (Wako), cobalt(II) acetylacetonate $\left(\mathrm{Co}(\mathrm{acac})_{2}\right)(>98 \%$, Acros) and 2,2,6,6-tetramethylpiperidine 1-oxy (TEMPO) (98\%, Aldrich) were used as received.

Characterization. Size exclusion chromatography (SEC) were carried out in DMF containing some $\mathrm{LiBr}(0.025 \mathrm{M})$, with a Waters 600 liquid chromatograph equipped with a 410 refractive index detector and styragel HR columns (HR1, 100-5000; HR3, 500-30000; HR4, 5000-500000; HR5, 2000-40000000). Poly(methyl methacrylate) standards were used for calibration. The molar masses of the PAN were corrected using the Mark-Houwink equation $\left([\eta]=\mathrm{K}_{\mathrm{n}} \mathrm{M}_{\mathrm{n}}{ }^{\mathrm{a}}\right.$, where $\mathrm{K}_{\mathrm{n}}=\mathrm{K}\left(\mathrm{M}_{\mathrm{w}} / \mathrm{M}_{\mathrm{n}}\right)^{0.5 \mathrm{a}(\mathrm{a}+1)}$ ) (in DMF, $\mathrm{K}_{\mathrm{PMMA}}=1.32 \times 10^{-4}, \mathrm{a}$ PMMA $=0.674 ; \mathrm{K}_{\mathrm{PAN}}=3.17 \times 10^{-4}, \mathrm{a}$ PAN $\left.=0.746\right) .{ }^{[30],[33]}{ }^{1} \mathrm{H} \mathrm{NMR}$ spectra were recorded in deuterated DMSO (DMSO-d $\mathrm{d}_{6}$ ) with a Bruker Spectrometer (250 MHz). Inductively Coupled Plasma Mass Spectrometry (ICPMS) was carried out 
with a Spectrometer Elan DRC-e Perkin Elmer SCIEX. Samples were prepared according to the following procedure: evaporation of $1 \mathrm{ml}$ of the cobalt adduct stock solution in $\mathrm{CH}_{2} \mathrm{Cl}_{2}$, treatment of the residue by $\mathrm{HNO}_{3}(65 \%)$ at $60^{\circ} \mathrm{C}$ for $2 \mathrm{~h}$, dilution with $250 \mathrm{ml}$ of doubly distilled water.

Typical procedure for the homopolymerization of acrylonitrile by CMRP in dimethylformamide . Co(acac) $)_{2}(102 \mathrm{mg}, 0.40 \mathrm{mmol})$ and $\mathrm{V}-70(122 \mathrm{mg}, 0.40 \mathrm{mmol})$ were added into a round bottom flask capped by a three-way stopcock, purged by three vacuum-argon cycles followed by subsequent addition of distilled and degassed DMF $(5.0 \mathrm{ml})$ and $\mathrm{AN}(5.0 \mathrm{ml}, 4.03 \mathrm{~g}, 76 \mathrm{mmol})$. The same procedure was repeated four times and all the reaction media were placed simultaneously in an oil bath at $30^{\circ} \mathrm{C}$. After few hours, the reaction mixture became inhomogeneous; a grey suspension appeared in the flasks. Each experiment was stopped at a different time by addition of $1 \mathrm{ml}$ of solution of TEMPO in DMF (500 mg TEMPO/ml). For each experiment, the conversion was measured gravimetrically after precipitation of the PAN into diethy ether whereas molar masses and molar mass distributions were determined by SEC (cfr characterization section).

Typical procedure for the homopolymerization of acrylonitrile by CMRP in dimethylsulfoxide. $\mathrm{Co}(\mathrm{acac})_{2}(102 \mathrm{mg}, 0.40 \mathrm{mmol})$ and $\mathrm{V}-70(122 \mathrm{mg}, 0.40 \mathrm{mmol})$ were added into a round bottom flask capped by a three-way stopcock and purged by three vacuum-argon cycles. After subsequent addition of distilled and degassed DMSO $(5 \mathrm{ml})$ and $\mathrm{AN}(5 \mathrm{ml}, 4.03 \mathrm{~g}, 76 \mathrm{mmol})$, the reaction medium was heated at $30^{\circ} \mathrm{C}$ under stirring. After $2 \mathrm{~h}$, the viscosity of the polymerization medium started to increase and several samples were picked out all along the polymerization. Few drops of each sample were diluted in deuterated DMSO containing TEMPO in order to measure the AN conversion by ${ }^{1} \mathrm{H}$ NMR $\left(298 \mathrm{~K}, \mathrm{D}_{1}=2 \mathrm{~s}, 16 \mathrm{scans}\right)$. The remaining fractions of each sample were solubilized in DMF containing TEMPO in order to measure the molecular parameters of the polyacrylonitrile by SEC. $\mathrm{M}_{\mathrm{n}}$ th at $100 \%=10100 \mathrm{~g} / \mathrm{mol}$. The same experiment was also carried out in DMSO using different $[\mathrm{AN}] /[\mathrm{Co}]$ or $[\mathrm{Co}] /[\mathrm{V}-70]$ ratios.

Homopolymerization of acrylonitrile initiated by low molecular weight cobalt(III) adducts. The procedure for the synthesis as well as the complete characterization of the low molecular weight cobalt(III) adduct are described in details in a recent paper. ${ }^{[16]} \mathrm{As}$ a rule, this cobalt adduct contains less than 4 vinyl acetate units on average end-capped by the $\mathrm{Co}(\mathrm{acac})_{2}$ complex $\left.\left(\left[\mathrm{Co}(\mathrm{acac})_{2}\left(-\mathrm{CH}\left(\mathrm{OCOCH}_{3}\right) \mathrm{CH}_{2}\right)_{<4}-\mathrm{R}_{0}\right)\right]\right) ; \mathrm{R}_{0}$ being the primary radical generated by $\mathrm{V}-70$ ). The complex was stored as a $\mathrm{CH}_{2} \mathrm{Cl}_{2}$ solution at $20^{\circ} \mathrm{C}$ under argon. The cobalt concentration of the stock solution was estimated as 0.10 $\mathrm{M}$ by inductively coupled plasma mass spectrometry (ICP-MS). In a round bottom flask capped by a three-way stopcock and purged by three vacuum-argon cycles, $1 \mathrm{ml}$ of the pink cobalt(III) adduct stock solution ([Co] $=0.10 \mathrm{M}, 0.10 \mathrm{mmol})$ was introduced and then evaporated to dryness under reduced pressure. The compound was then dissolved in distilled and degassed DMSO $(5 \mathrm{ml})$, followed by the addition of distilled and degassed AN $(5 \mathrm{ml}, 4.06 \mathrm{~g}, 75.2 \mathrm{mmol})$. The reaction mixture was then stirred at $30^{\circ} \mathrm{C}$ The AN conversion and the molecular parameters of the PAN were determined at different times by ${ }^{1} \mathrm{H}$ NMR and the SEC, respectively, as described above. The same experiment was repeated at $0^{\circ} \mathrm{C}$

Typical procedure for the preparation of $\mathrm{Co}(\text { acac })_{2}(L)_{2}$ crystals and their X-ray analysis. $\mathrm{Co}(\mathrm{acac})_{2}(600 \mathrm{mg}, 2.34 \mathrm{mmol})$ was added into a round bottom flask cappe by a three-way stopcock and purged by three vacuum-argon cycles and dissolved at room temperature in dry and degassed solvents $(6.0 \mathrm{ml})$, i.e. AN, DMF or DMSO. After stirring for $4 \mathrm{~h}$, the solutions were transferred under argon into another flask before dilution with an equal volume of dry and degassed acetone. The mixtures were cooled down at $-20^{\circ} \mathrm{C}$ in order to crystallize the cobalt complexes. Following this procedure orange crystals of $\mathrm{Co}(\mathrm{acac})_{2}(\mathrm{DMF})_{2}$ and $\mathrm{Co}(\mathrm{acac})_{2}(\mathrm{DMSO})_{2}$ were recovered and analyzed by X-Ray whereas the same experiment conducted with of AN did not lead to crystallization.

X-ray data were collected on an Oxford Diffraction Gemini R Ultra diffractometer using monochromated Mo K $\alpha$ radiation. Crystals of the $\mathrm{Co}(\mathrm{acac})_{2}(\mathrm{DMSO})_{2}$ belong to space group $\mathrm{P} 21 / \mathrm{c}$, with unit-cell parameters $a=8.789(5), b=12.490(5), c=8.789(5) \AA$ and $\beta=99.404(5)^{\circ}$. Crystals of the $\mathrm{Co}(\mathrm{acac})_{2}(\mathrm{DMF})_{2}$ belong to space group $\mathrm{P}-1$, with unit-cell parameters $a=6.1871(2), b=9.0988(4), c=9.6922(4) \AA$ and $\alpha=70.630(4)$, $\beta=74.294(3), \gamma=78.940(3)^{\circ}$. The data were processed using the CrysAlis package ${ }^{[45}$. The structure was solved with Sir92 $2^{[46]}$ and refined using SHELXL97 ${ }^{[47]}$ for full-matrix least-squares refinement. Crystal structures were refined against low temperature data CCDC-679089 \& 679090 contains the supplementary crystallographic data for this paper. These data can be obtained free of charge from the Cambridge Crystallographic Data Centre via www.ccdc.cam.ac.uk/data_request/cif.

Computational details. All geometry optimizations were performed using the B3LYP three-parameter hybrid density functional method of Becke, ${ }^{[48]}$ as implemented in the Gaussian03 suite of programs. ${ }^{[49]}$ The basis functions consisted of the standard 6-31G** for all light atoms $(\mathrm{H}, \mathrm{C}, \mathrm{N}, \mathrm{O})$, plus the LANL2DZ function, which included the Hay and Wadt effective core potentials (ECP) ${ }^{[50]}$ for Co. The latter basis set was however augmented with an $f$ polarization function $(\alpha=0.8)$ in order to obtain a balanced basis set and to improve the angular flexibility of the metal functions. All geometry optimizations were carried out without any symmetry constraint and all final geometrie were characterized as local minima of the potential energy surface (PES) by verifying that all second derivatives of the energy were positive. The unrestricted formulation was used for open-shell molecules. The value of $\left\langle\mathrm{S}^{2}\right\rangle$ at convergence was very close to the expected value of 0.75 for the radical species and 3.75 for the spin quartet species [the greatest deviation was 3.7573 for complex $\mathrm{Co}(\mathrm{acac})_{2}\left(\mathrm{CH}_{2}=\mathrm{CHCN}\right)$ ], indicating minor spin contamination. All energies were corrected for zero point vibrational energy and for thermal energy to obtain the bond dissociation enthalpies at $298 \mathrm{~K}$. The standard approximations for estimating these corrections were used (ideal gas, rigid rotor and harmonic oscillator) as implemented into Gaussian03. Additional calculations were also carried out with the same basis set by use of the B3PW91* functional, at the fixed geometries optimized by B3LYP. The thermal enthalpy correction was carried out using the B3LYP values. The B3PW91* functional is a modified version of the B3PW91 functional, in which the $c_{3}$ coefficient in Becke's original three-parameter fit to thermochemical data was changed to 0.15 .

\section{Acknowledgements}

The authors from Liège are indebted to the "Belgian Science Policy" for financial support in the frame of the "Interuniversity Attraction Poles Programme (PAI VI/27) Functional Supramolecular Systems", and to the "Fonds National de la Recherche Scientifique" (F.N.R.S., Belgium). A. D. and C.M. are "Chargés de Recherche" by F.N.R.S and C. D. is "Chercheur Qualifié" by F.N.R.S. R.P. thanks the "Agence National de la Recherche" (Contract No. NT05-2_42140) and the "Centre Interuniversitaire de Calcul de Toulouse" (Project CALMIP) for granting free computational time. The authors also express their thanks to Dr. Jeremy N. Harvey for fruitful discussions, Professor J. Wouters for giving access to the X-Ray facilities, G. Cartigny and B. Norberg for skilful assistance and Wako for kindly providing them with V70.

[1] M. K. Georges, R. P. N. Veregin, P. M. Kazmaier and G. K. Hamer, Macromolecules 1993, 26, 2987-2988.

[2] W. A. Braunecker and K. Matyjaszewski, Prog. Polym. Sci. 2007, 32, 93-146.

[3] C. J. Hawker, A. W. Bosman and E. Harth, Chem. Rev. 2001, 101, 3661-3688.

[4] V. Sciannamea, R. Jerome and C. Detrembleur, Chem. Rev. 2008, 108, 1104-1126.

[5] C. Barner-Kowollik, Handbook of RAFT polymerization 2008, Ed. Wiley VCH.

[6] B. B. Wayland, G. Poszmik, S. L. Mukerjee and M. Fryd, J. Am. Chem. Soc. 1994, 116, 7943-7944.

[7] B. B. Wayland, L. Basickes, S. Mukerjee, M. Wei and M. Fryd, Macromolecules 1997, 30, 8109-8112.

[8] B. B. Wayland, C.-H. Peng, X. Fu, Z. Lu and M. Fryd, Macromolecules 2006, 39 , 8219-8222.

[9] A. Debuigne, J.-R. Caille and R. Jerome, Angew. Chem., Int. Ed. 2005, 44, 11011104.

[10] R. Bryaskova, C. Detrembleur, A. Debuigne and R. Jerome, Macromolecules 2006 39, 8263-8268.

[11] H. Kaneyoshi and K. Matyjaszewski, Macromolecules 2005, 38, 8163-8169.

[12] S. Maria, H. Kaneyoshi, K. Matyjaszewski and R. Poli, Chem. Eur. J. 2007, 13, 2480-2492.

[13] A. Debuigne, J.-R. Caille and R. Jerome, Macromolecules 2005, 38, 5452-5458.

[14] A. Debuigne, J.-R. Caille, C. Detrembleur and R. Jerome, Angew. Chem., Int. Ed. 2005, 44, 3439-3442.

[15] C. Detrembleur, A. Debuigne, R. Bryaskova, B. Charleux and R. Jerome, Macromol. Rapid Commun. 2006, 27, 37-41.

[16] A. Debuigne, Y. Champouret, R. Jérôme, R. Poli and C. Detrembleur, Chem. Eur. J. 2008, 14, 4046-4059.

[17] A. Debuigne, J.-R. Caille, N. Willet and R. Jerome, Macromolecules 2005, 38, 9488-9496.

[18] R. Bryaskova, N. Willet, A. Debuigne, R. Jerome and C. Detrembleur, J. Polym. Sci., Polym. Chem. 2006, 45, 81-89.

[19] R. Bryaskova, N. Willet, P. Degee, P. Dubois, R. Jerome and C. Detrembleur, J. Polym. Sci., Polym. Chem. 2007, 45, 2532-2542.

[20] A. Debuigne, N. Willet, R. Jerome and C. Detrembleur, Macromolecules 2007, 40, 7111-7118.

[21] A. Debuigne, J. Warnant, R. Jérôme, I. Voets, A. D. Keizer, M. A. C. Stuart and C. Detrembleur, Macromolecules 2008, 41, 2353-2360.

[22] D. Benoit, V. Chaplinski, R. Braslau and C. J. Hawker, J. Am. Chem. Soc. 1999, $121,3904-3920$

[23] C. Tang, T. Kowalewski and K. Matyjaszewski, Macromolecules 2003, 36, 1465 1473 .

[24] A. Kaim, J. Polym. Sci., Polym. Chem. 2006, 45, 232-241.

[25] K. Matyjaszewski, S. M. Jo, H.-J. Paik and S. G. Gaynor, Macromolecules 1997, 30, 6398-6400.

[26] K. Matyjaszewski, S. M. Jo, H.-J. Paik and D. A. Shipp, Macromolecules 1999, 32 6431-6438.

[27] B. Barboiu and V. Percec, Macromolecules 2001, 34, 8626-8636.

[28] C. Tang, T. Kowalewski and K. Matyjaszewski, Macromolecules 2003, 36, 8587 8589.

[29] Q. An, J. Qian, L. Yu, Y. Luo and X. Liu, J. Polym. Sci., Polym. Chem. 2005, 43, 1973-1977.

[30] X.-H. Liu, Y.-G. Li, Y. Lin and Y.-S. Li, J. Polym. Sci., Polym. Chem. 2007, 45, $1272-1281$

[31] X.-H. Liu, G.-B. Zhang, X.-F. Lu, J.-Y. Liu, D. Pan and Y.-S. Li, J. Polym. Sci., Polym. Chem. 2005, 44, 490-498. 
[32] A. Aqil, C. Detrembleur, B. Gilbert, R. Jerome and C. Jerome, Chem. Mat. 2007, $19,2150-2154$

[33] M. Minagawa, K. Miyano, T. Morita and F. Yoshii, Macromolecules 1989, 22 , 2054-2058.

[34] F. Calderazzo, G. Pampaloni, D. Vitali, I. Collamati, G. Dessy and V. Fares, $J$ Chem. Soc., Dalton Trans. 1980, 1965-1969.

[35] C. Carini, C. Pelizzi, G. Pelizzi, G. Predieri, P. Tarasconi and F. Vitali, J. Chem. Soc., Chem. Comm. 1990, 613-614.

[36] G. M. Chiarella, D. Y. Melgarejo and S. A. Koch, J. Am. Chem. Soc. 2006, 128, 1416-1417.

[37] J. Conradie and A. Ghosh, J. Chem. Theory Comput. 2007, 3, 689-702.

[38] I. H. Wasbotten and A. Ghosh, Inorg. Chem. 2007, 46, 7890-7898.

[39] O. Salomon, M. Reiher and B. A. Hess, J. Chem. Phys. 2002, 117, 4729-4737.

[40] J. N. Harvey and M. Aschi, Faraday Disc. 2003, 124, 129-143.

[41] J. N. Harvey and R. Poli, Dalton Trans. 2003, 4100-4106.

[42] J.-L. Carreón-Macedo and J. N. Harvey, J. Am. Chem. Soc. 2004, 126, 5789-5797.

[43] M. B. Gillies, K. Matyjaszewski, P.-O. Norrby, T. Pintauer, R. Poli and P. Richard, Macromolecules 2003, 36, 8551-8559.

[44] K. Matyjaszewski and R. Poli, Macromolecules 2005, 38, 8093-8100.

[45] Oxford Diffraction (2007). CrysAlis CCD and CrysAlis RED. Versions 1.171.32.5. Oxford Diffraction Ltd, Abingdon, Oxfordshire, England

[46] A. Altomare, G. Cascarano, C. Giacovazzo and A. Guagliardi, J. Appl. Cryst. 1993, 26, 343-350

[47] Sheldrick, G. M. (1997). SHELXL-97. A program for crystal structure refinement. University of Goettingen, Germany, release 97-2

[48] A. D. Becke, J. Chem. Phys. 1993, 98, 5648-5652.
[49] G. W. T. M. J. Frisch, H. B. Schlegel, G. E. Scuseria, M. A. Robb, J. R.

Cheeseman, J. Montgomery, J. A., T. Vreven, K. N. Kudin, J. C. Burant, J. M.

Millam, S. S. Iyengar, J. Tomasi, V. Barone, B. Mennucci, M. Cossi, G. Scalmani,

N. Rega, G. A. Petersson, H. Nakatsuji, M. Hada, M. Ehara, K. Toyota, R. Fukuda,

J. Hasegawa, M. Ishida, T. Nakajima, Y. Honda, O. Kitao, H. Nakai, M. Klene, X.

Li, J. E. Knox, H. P. Hratchian, J. B. Cross, C. Adamo, J. Jaramillo, R. Gomperts,

R. E. Stratmann, O. Yazyev, A. J. Austin, R. Cammi, C. Pomelli, J. W. Ochterski,

P. Y. Ayala, K. Morokuma, G. A. Voth, P. Salvador, J. J. Dannenberg, V. G.

Zakrzewski, S. Dapprich, A. D. Daniels, M. C. Strain, O. Farkas, D. K. Malick, A.

D. Rabuck, K. Raghavachari, J. B. Foresman, J. V. Ortiz, Q. Cui, A. G. Baboul, S.

Clifford, J. Cioslowski, B. B. Stefanov, G. Liu, A. Liashenko, P. Piskorz, I.

Komaromi, R. L. Martin, D. J. Fox, T. Keith, M. A. Al-Laham, C. Y. Peng, A

Nanayakkara, M. Challacombe, P. M. W. Gill, B. Johnson, W. Chen, M. W. Wong,

C. Gonzalez, J. A. Pople,, Gaussian 03, Revision C.02, Gaussian, Inc., Wallingford

CT 2004

[50] P. J. Hay and W. R. Wadt, J. Chem. Phys. 1985, 82, 270-283.

Received: ((will be filled in by the editorial staff))

Revised: ((will be filled in by the editorial staff)) Published online: ((will be filled in by the editorial staff)) 
Metal-coordination: a powerful lever for cobalt mediated radical polymerization.

A. Debuigne, C. Michaux, C. Jérôme, R. Jérôme, R. Poli*, C. Detrembleur*

Cobalt Mediated Radical

Polymerization of Acrylonitrile :

Kinetics Investigations and DFT

Calculations
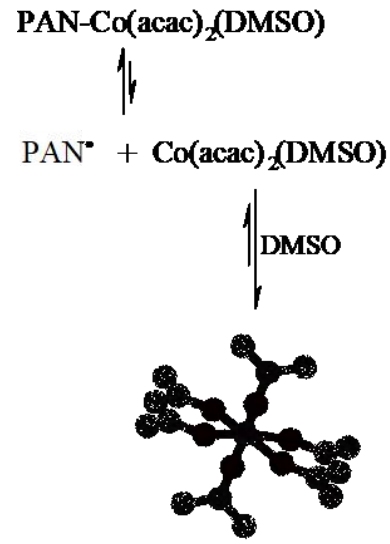

Experimental and computational studies show how solvent coordination fine tunes the $\mathrm{Co}^{\mathrm{II}}(\mathrm{acac})_{2}$ system for the synthesis of well controlled poly(acrylonitrile) (PAN) and poly(vinyl acetate)-bpoly(acrylonitrile) (PVAc- $b$-PAN) block copolymers. 